\title{
Beiträge zur pathologischen Anatomie der traumatischen Aniridie und Iridodialyse.
}

\author{
Ton \\ Dr. Hugo Wintersteiner, \\ Assistenten a. d. Augenklinik des Hofrathes Prof.Stellwag ron Carion \\ in Wien.
}

Hierzu Tafel I nnd II, Fig. 1-16.

Während in der Iiteratur sich zahlreiche klinische Beobachtungen von Irideremia traumatica und Iridodialyse vorfinden, deren Veröffentlichung zumeist durch besondere nerkwürdige Umstände des Falles oder durch einzelne interessante Symptome oder Complicationen veranlasst wurde, sind die anatomischen Untersuchungen ïber diesen Gegenstand noch ïberaus spärlich. Der Grund hierfür liegt offenbar in der Schwierigkeit, das Untersuchungsmaterial zu beschaffen; denn derartig verletzte Augen geben verhältnissmässig selten Veranlassung zur Enucleation wegen Gefahr der sympathischen Erkrankung des anderen Auges oder wegen hinzugetretener Drucksteigerung und lange dauernder Schmerzhaftigkeit oder ähnlichen für den Kranken gefährlichen oder quälenden Zuständen.

Von histologischen Arbeiten iiber Irideremie und Iridodialyse sind nur zwei verwerthbar, nämlich die von Treitel und von Schäfer, auf welche ich noch wiederholt zurückkommen werde. Die früheren Publicationen von Maats und Lawson bringen nur je eine kurze makro*

จ. Graefe's Archiv für Ophthalmologie, XI, 2. 
skopische Beschreibung eines Bulbus mit Irideremie und Aphakie. Die beiden in den Arbeiten von Alt und Schiess-Gemuseus beschriebenen, histologisch untersuchten Fälle sind, da die Untersuchung andere Ziele verfolgte, gerade bezüglich der Verhältnisse im Kammerwinkel so aphoristisch gehalten, dass sie für die pathologische Anatomie der Iridodialyse resp. Irideremie ganz belanglos erscheinen.

Ich muss es deshalb als einen gïnstigen Zufall betrachten, dass ich im Laufe des vorigen Jahres zwei delartige Fälle, welche auch zur Enucleation kamen, beobachten konnte und ausserdem in der Sammlung der I. Augeuklinik je einen älteren Bulbus mit Tridodialyse und mit Irideremia traumatica vorfand und zur Untersuchung verwenden konnte.

Es drängt mich, bei dieser Gelegenheit meinem verehrten Chef, Herrn Hofrath Prof. Stellwag von Carion für die bereitwillige Ueberlassung des Untersuchungs-Materiales und der Krankenprotokolle meinen aufrichtigen Dank auszusprechen.

Zuerst mögen nun die Krankengeschichten und histologischen Befunde der vier Fälle folgen:

\section{Fall I.}

Leopold Taubach, 40 Jahre alt, Knecht, sub Prot. Nr. 27, Journ.-Nr, 4288, am 2. März 1892 anfgenommen.

Am 15. Januar flog ihm bei dex Arbeit ein hölzerner Maschinenbestandtheil gegen das linke Auge. Dasselbe soll sogleich erblindet sein und entzundete sich in der Folge. Da der Kranke nichts sah und die Entzündung nicht abuahm, kam er in die Klinik, wobei sich folgende Verhältnisse feststellen liessen.

Am l. A. sind die Lider geschwollen und bläulichroth. Ihre Bindehaut lebhaft injicirt and reichlich secernirend. Der Bulbus ciliar geröthet. Etwa $2 \mathrm{~mm}$ von der oberen Corneoskleralgrenze entfernt verłauft mit derselben parallel ein etwa 8 min breiter, der vierten Theil des Hornhautumianges um- 
Beiträge zur patholog. Anatomie d. traumatischen Aniridie etc. 3

greifender, schwarzblauer Wulst von $1 \frac{1}{2} \mathrm{~cm}$ Länge, welcher auf $1 / 2 \mathrm{~cm}$ über die Bulbusoberfläche vorragt und nur von Conjunctiva bedeckt wird. Die vorderen Ciliargefässe treten hinter demselben durch die Sklera. Die Hornhaut ist gestichelt, in der oberen Halfte abgeflacht, im Ganzen zart diffus getribt und besonders in der äusseren Hälfte von zahlreichen, grauweissen, horizontal verlaufenden, parallelen, tiefliegenden Linien durchzogen, welche am Hornhautrande beginnen und bis über die Hornhautmitte hineinreichen.

Der ganze Raum hinter der Hornhaut erscheint von tiefschwarzer Farbe und lässt nur bei gewisser Stellung im concentrirten Lichte einen rubinrothen, aus der Tiefe kommenden Reflex erkennen. Von der Iris ist nur aussen oben ein ganz schmaler (1 mm breiter), bei $6 \mathrm{~mm}$ langer Streifen von grattgrünlicher Farbe sichtbar, welcher sich mit einer scharfen geradlinigen Grenze gegen das vergrösserte Pupillargebiet absetzt, sonst ist nirgends ein Rest von ihr aufzufinden. Die Anwesenheit der Linse kann nicht sicher constatirt werden. Der Fundus ist nicht sichtbar, die Spannung etwas vermehrt, das Sehvermögen auf Lichtempfindung beschränkt. Der Bulbus ist auf Druck und spontan sehr schmerzhaft.

Die Diagnose wurde auf traumatisches Skleralstaphylom mit Irideremie und Keratitis striata traumatica gestellt. Es konnte nicht entschieden werden ob die Iris oder die Chorioidea resp. der Ciliarkörper prolabirt waren, doch sprach die bedeutende Vorwölbung und relativ grosse Entfernung des Staphyloms vom Corneoskleralrande mehr für letztere Annahme. Der Hämophthalmus liess auch nicht erkennen, ob die Linse vorhanden war oder fehlte.

Da die Reizerscheinungen und die Schmerzhaftigkeit des Bulbus fortbestanden, wurde am 11. März die Enucleation vorgenommen, am 15. März 1892 der Kranke entlassen.

Makroskopische Untersuchung des im verticalen Meridian halbirten Bulbus:

Es fällt vor Allem die bedeutende Grösse und Flachheit der Hornhaut auf, welche gleichzeitig diunner als gewöhnlich ist. Von Iris und Linse ist nichts auffindbar. Der Kammerranm wird von dem des Glaskörpers durch eine nach vorne zu leicht concave Membran getrennt, welche sich ringsum in der Gegend der Kammerbucht ansetzt. In der Kammer einige graue, feinkörnige Gerinnsel. Der Glaskörper von zarten Membranen durchsetzt, blutig braunroth gefärbt. 
An der dem Skleralstaphylom entsprechenden Stelle befindet sich zwischen Sklera und Bindehaut ein flachgedrückter, $1 \mathrm{~mm}$ hoher und $5 \mathrm{~mm}$ breiter Hohlraum, welcher durch eine enge, an der Corneoskleralgrenze gelegene Spalte mit dem Bulbusinneren in Verbindung steht. Seine Wandung ist wellig und schwarzbraun pigmentirt, sein Inhalt grössten Theils flüssig; er öffnet sich erst hinter dem vorerwähnten Diaphragma, communicirt also mit dem Glaskörperraum, nicht mit der Kammer. Der Ciliarkörper ist sehr flach, seine Fortsätze klein. Netzhaut und Aderhaut zeigen bezüglich ihrer Lage und ibres Aussehens nichts Krankhaftes, der Sehnerv ist makroskopisch unverändert.

Mikroskopische Untersuchung. (Fig. 1.)

Die Hornhaut ist mit normalem Epithel überkleidet. Die Bowman'sche Membran zeigt an mehreren Stellen seichte Einknickungen, in welche sich das Epithel einsenkt, ohne an der Oberfläche dieselben zum Ausdrucke zu bringen. Das Hornhautgewebe ist dicht, die Lymphspalten nieht erweitert, keine Spur einer zelligen Infiltration. Die Membrana Descemetii macht mehrere grobe, in die Vorderkammer fast spitzwinkelig vorspringende Falten, welche von dem unversehrten Endothel überzogen sind. Auch die hinteren Hornhautschichten zeigen die gleiche Faltung; doch gleicht sie sich allmählich nach vorne zu immer mehr aus, bis an der Grenze des mittleren und vorderen Drittels der Hornhautdicke auch die letzte zarte Wellung der Lamellen geschwunden ist.

Der Kammerwinkel bietet mit Ausnabme der Stelle, wo die Skleralruptur sich befindet, im ganzen Umkreis ziemlich gleiche Verbältnisse. In dieser ganzen Ausdehnung fehlt die Iris vollständig, keine Spur von ihr ist an ihrer Ansatzstelle zurückgeblieben. Der Schlemm'sche Canal ist erhalten und unverletzt. Das Balkenwerk des Ligamentum pectinatum ist zusammengefallen, dicht aneinander gedrängt und von freien Pigmentkörnchen und pigmentführenden Zellen durchsetzt, welche auch in die tiefsten Skleralschichten eindringen und sich in der nächsten Umgebung des Schlemm'schen Canales vorfinden.

Die Ciliarfortsätze sind sämmtlich nach vorne gerichtet und weiter nach vorne gelagert, ein Theil direct nach vorne gezerrt, indem sie mit ihrer Basis, welche der Abrissstelle der Iris entspricht, an das Ligamentum pectinatum ohne Schalt- 
gewebe angelöthet sind. Auf diese Weise wird auch die vordere Fläche des Ciliarmuskels, welche durch die Abreissung der Iris blossgelegt worden war, vollständig gedeckt, und die Spitzen der Processus ciliares liegen gerade an der Grenze der Descemet'schen Haut oder überragen dieselbe noch um ein Geringes nach vorne zu. Einige von den Fortsätzen, welche mit ihren Firsten nicht so weit nach vorne reichen, sind durch feinfaseriges, den Zonulafasern gleichendes, und von etlichen Zellen durchsetztes Gewebe, welches auch Pigment in Körnchen und Schollen führt, an das Ligamentum pectinatum fixirt, ohne mit ihm direct in Contact zu treten. Der Ciliarkörper zeigt sonst keine Veränderungen.

Im oberen Umfange erscheint die Sklera ganz nahe an der cornealen Grenze der Quere nach vollständig durchrissen, die Rissränder bis auf $2 \mathrm{~mm}$ klaffend. Die äusseren Schichten der Sklera haben sich bedeutend stärker zurückgezogen als die inneren, daher schärfen sich die Ränder von aussen etwas zu. Die Ruptur geht genau durch die Gegend des Schlemm'schen Canales, von welchem sich keinerlei Reste auffinden lassen. Die Cornea ist hier an ihren Randparthien von kleinen, zwischen den Lamellen liegenden und zum Theile von Rundzellen eingescheideten Gefässchen durchzogen. Die Bindehaut ist emporgehoben und etwas verdünnt. Sowohl die Conjunctiva als auch das subconjunctivale Gewebe zeigen eine auffällige Pigmentirung. Bei schwacher Vergrösserung erscheint sie in Form einer ziemlich gleichförmig ausgebreitoten, doch stellenweise auch gruppirten, schwarzen Punktirung (Fig. 2); bei stärkerer Vergrösserung erkennt man, dass das Pigment eine bestimmte Vertheilung einnimmt.

Vorerst finden sich Schollen und Klümpchen von der 1-4 fachen Grösse eines rothen Blutkörperchens, welche aus zahlreichen, kleinen, sepiabraunen Köruchen zusammengesetzt scheinen, frei in den Lymphgefässen, hauptsächlich in den Lymphscheiden der Blutgefässe liegend (Fig. 3). Sie geben sich jedoch bei entsprechender Vergrösserung und besonders bei Anwendung des Abbé'schen Beleuchtungsapparates als Leukocyten za erkennen, welche mit Pigment beladen sind, da man zwischen den dunklen Körnchen den durch Karmin roth gefärbten Kern hindurchschimmern sieht, und anderseits wieder Lymphzellen zu finden sind, welche nur einige wenige Körnchen in ihrem Plasma enthalten. Stellenweise liegen diese pigmentführenden Zellen so dicht aneinander, dass ein kleines 
Blutgefäss wie von einem schwarzbraunen Ringe, der nur hier und da eine Verschmälerung oder Unterbrechung zeigt, umschlossen ist (vgl. Fig. 2).

Weiterhin tritt das Pigment auch im Bindegewebe der Conjunctiva und Subconjunctiva auf (Fig. 4). Es liegt in Gestalt kleiner Körnchen manchmal in den Bindegewebsfasern und erzeugt, da ein Körnchen hinter dem andern perlschnurartig angeordnet liegt, kürzere und längere, in sanften Wellen verlaufende, punktirte Linien. Zumeist ist es jedoch knapp um die Bindegewebskerne stärker angehäuft, so dass ein Ende des spindelförmigen Kernes braun, das andere mit Karmin roth gefärbt erscheint; oder es sind beide spitze Enden des Kernes pigmentirt, die Mitte roth, oder endlich es ist der ganze Kern von einer braunen Pigmenthülle umgeben. Die Vertheilung dieser beiden Sitze des Pigments (in den Fasern und in den Zellen) ist zumeist derart, dass in der eigentlichen Conjunetiva fast nur Fasern und auch diese nur spärlich pigmentirt sind, während im subconjunctivalen Gewebe vorwiegend der zarte Protoplasmaleib der Bindegewebszelle den Farbstoff enthält. Ganz nahe unter dem Epithel finden sich im conjunctivalen Gewebe auch Pigmentkörnchen einzeln und gehäuft, von welchen es sich nicht mit Sicherheit ausschliessen lässt, dass sie frei $\mathrm{zw}$ ischen den Gewebselementen liegen. Doch ist es viel wabrscheinlicher dass es sich hier nur um Querschnitte von pigmentführenden Bindegewebsfasern handelt, zumal da auch in den der Länge nach getroffenen Bindegewebsbündeln nirgends Körnchen zwischen, sondern stets nur in den Fasern nachzuweisen sind.

Schliesslich findet sich das Pigment allenthalben im Gewebe verstreut an Zellen gebunden, welche wie die in den Lymphgefässen befindlichen vorerst ebenfalls den Eindruck von schwarzen Klümpchen und Schollen machen. Es lässt sich jedoch stets im Centrum ein in seiner Form häufig nicht deutlich erkennbarer, rothgefärbter Kern nachweisen, welcher von einer mehr minder mächtigen Protoplasmahülle umgeben ist; und in dieser letzteren allein findet sich das aus zahllosen Körnchen bestehende Pigment. Es sind offenhar Wanderzellen, welche mit dem Transporte des Pigmentes beschäftigt sind. $\mathrm{Ob}$ es nun solche Zellen sind, welche den Farbstoff herbeiführen, um ihn im Gewebe zu deponiren, oder solche, welche ihn aus dem Gewebe wieder aufgenommen haben, um ihn gegen die Lymphdrüsen abzuführen, dürfte kaum mit Sicher- 
heit jemals zu entscheiden sein. Ich halte dafür, dass beide Funktionen wohl gleichzeitig stattfinden werden, indem ein Theil der Lenkocyten noch fortwahrend neues Pigment herbeischleppt, während ein anderer Theil schon mit dem Weiterführen desselben begonnen hat, Als Zellen, welche der letzteren Function obliegen, bin ich geneigt, die in den Lymphgefässen befindlichen pigmentführenden Leukocyten aufzufassen.

Im Allgemeinen ist das Epithel der Bindehaut frei von Pigment. Nur die basale und die unmittelbar darauf folgende Schicht enthält ganz vereinzelt stehende Zellen, deren Leib mit glänzenden, schwarzbraunen, vielkantigen Körnchen mehr oder weniger erfüllt ist (Fig. 5). Meist sind sie an einem Pole der Zelle mehr angehäuft and erzengen, da sie nur in den periphersten Parthien des Protoplasma liegen, den Eindruck einer grösseren oder kleineren Kappe, welche der Zelle aufsitzt. Durch diese periphere Lage des Pigmentes werden die Contouren derjenigen Zellen, in welchen dasselbe reichlicher angesammelt ist, ausserordentlich deutlich ausgeprägt, ähnlich wie in den schon früher erwähnten Wander- und Bindegewebszellen.

Endlich finden sich in der Bindehaut noch Nester von Rundzellen, welche besonders die Gefässe scheidenartig umgeben.

Der Ciliarkörper ist auch an der Rupturstelle wohl erhalten, ohne Verletzung. Die Iris ist von ihm nicht abgelöst, doch ist sie durch die Skleralwunde vorgefallen und hat sich mit ihrer früheren Vorderfäche unmittelbar an die Aussenseite der Sklera angelegt und kleidet, mit ihrem pupillaren Theile wieder nach vome umbiegend, die ganze hintere Hälfte des zwischen Sklera und Conjunctiva gelegenen Hohlraumes aus. Sie ist dabei ziemlich stark gedehnt und verdünnt, mit der Sklera und dem subconjunctivalen Gewebe fest verwachsen, ihre Grenzen jedoch an jeder Stelle noch deutlich erkennbar. Stellenweise hat sich an dem Wundrande der Sklera junges Bindegewebe mit ziemlich zablreichen grossen Kernen angebildet, welches sich zwischen Sklera und die ihr sonst Innig anliegende Iris als sehr verschieden dicke Lage einschiebt. Auffallend ist, dass die freie Oberfläche der Iris, d. h. ihre frühere Hinterfläche keinen Pigmentbelag trägt. Derselbe hat sich nämlich von ihr abgelöst und bildet die Auskleidung der vorderen Hälfte des Staphylomes. Der Sphincter iridis ist ganz deutlich zu unterscheiden und zeigt keine auf- 
fällige Atrophie. Die Iris ist nur wenig zellig infiltrirt, ihre Gefässe dicht aneinander gedrängt.

Nahe an der Rupturstelle findet sich im Bulbusraume noch ein Stuck Iris auf den Schnitten vor, dasselbe liegt frei, d. h. von seiner ciliaren Anheftung abgetrennt ungefähr in der normalen Irisebene ausgebreitet mit dem Rissrande dem Ciliarkörper zugewendet, mit dem Pupillarrande nach der Bulbusachse gekehrt. Es ist umgesehlagen, so dass die pigmentirte Fläche nach vorne sieht; ausserdem ist der Pupillarrand gegen das Pigmentblatt $\mathrm{zu}$ eingerollt. Diese Umstülpung ist durch ein zartfaseriges Gewebe, in welches nur spärliche Kerne eingelagert sind, fixirt, indem dasselbe als ununterbrochenes Häutchen die ganze jetzt nach vorne sehende Fläche der Regenbogenhaut überzieht und sich von da weiter in der Richtung nach der gegenüberliegenden Kammerbucht diaphragmaartig fortsetzt. Die nach hinten sehende Fläche der Iris ist ebenfalls von einem zarten, aus Fasern bestehenden Häntchen überkleidet, welches gerade gegen die Ciliarfortsätze hinzieht und sich an denselben ansetzt. Der Rissrand der Iris ist zerfranzt, zackig, stellenweise durch loekeres neugebildetes Gewebe mit den fremden Ciliarfortsătzen verbunden. Oftenbar handelt es sich um den Theil der Iris, dessen normaler Ansatz unten, also der Ruptur diametral gegenüber sich befindet und welcher nur durch den Vorfall der übrigen Regenbogenhaut herübergezerrt wurde.

In den weiter seitlich fallenden Schnitten sind diese klaren VerhäItnisse der Iris mehr verwischt, da sie vielfach gefaltet ist und sich schief stellt, so dass sie mit dem ciliaren Rissende nach hinten, mit dem Pupillarrande nach vorne sieht. Dieser letztere tritt dann mit der vorderen Lefze der Skleralwunde durch lockeres Bindegewebe in Verbindung. - Zwischen den Ciliarfortsätzen, welche wie der Ciliarkörper selbst ganz normale Verhältnisse zeigen, liegt feinfädig geronnenes Fibrin, untermengt mit zahlreichen rothen Blutkörperchen, welche stellenweise bedentend über die Gerinnsel überwiegen.

Die Zonulafasern sind im Bereiche des flachen Theiles des Ciliarkörpers allenthalben deutlich zu unterscheiden und liegen in ganz normaler Orientierung, in der Gegend der Ciliarfortsätze sind keine Zonulafasern mehr nachweisbar. Von der Linse und ihrer Kapsel ist nirgends im Bulbus eine Spur aufzufinden. Der hintere Augapfelabschnitt ist bis auf die blutige Imbibition und Zerwerfung des Glaskörpers normal. 
Beiträge zur patholog. Anatomie d. traumatischen Aniridie etc. 9

Nach der histologischen Untersuchung ist es num möglich die klinische Diagnose theils zu ergänzen, theils zu corrigiren und auch die mechanischen Vorgänge bei der Verletzung einigermassen klarzustellen.

Offenbar war durch den Stoss die Sklera in ihrer oberen Peripherie geborsten an der gewöhnlichen Stelle, welche nach den verschiedensten Untersuchungen als der schwächste Theil bekannt ist und sich auch durch besondere Dünnheit bei der mikroskopischen Untersuchung auszeichnet, nämlich zwischen Corneoskleralrand und Tnsertion des (oberen) geraden Augenmuskels. Durch die Ruptur fiel mit dem vorstürzenden Kammerwasser die Tris und Linse vor; da jedenfalls auch eine Zerreissung der Bindehaut stattgefunden hatte, so ging die Linse vollständig verloren, während die Regenbogenhaut, die sich jedenfalls schon im Momente der Bulbusruptur von ihrem Ciliaransatze in grosser Ausdehnung losgelöst hatte, offenbar von der herausgeschleuderten Linse mitgerissen wurde, jedoch gerade an der Stelle der Skleralruptur hängen und deshalb theils intra-, theils extrabulbär. liegen blieb. Dabei hatte sich der freigewordene Streifen Tris eingerollt und umgeschlagen. Da natürlich das Kanmerwasser abgeflosseı war, so lag die vorgefallene Iris zwischen Sklera und Bindehaut eng eingebettet und erst als der Humor aqueus sich wieder hergestellt hatte, wurde die Iris sammt der ïber sie hinziehenden und an der Rissstelle bald wieder verklebten Bindehaut wulstförmig ausgedehnt. Inzwischen hatte aber schon das Pigmentblatt der Iris eine Verklebung mit dem subconjunctivalen Gewebe eingegangen und blieb nun an demselben hängen, ähnlich wie es nach Lösung hinterer Synechieen an der Linsenkapsel haften bleibt. Auf diese Weise erklärt es sich leicht, dass nur die vordere Hälfte des Staphylomes innen einen Pigmentüberzug trägt, während derselbe an dem von Iris ausgekleideten Theile fehlt.

Was die an meisten interessirenden Veränderungen 
im Kammerwinkel betrifft, so sei nur kurz zusammengefasst: Die Iris ist vollständig ausgerissen, ohne einen Stumpf zurückzulassen. Die dadurch entstandene Wunde, welche auch das Ligamentum pectinatum (das Zeichen von Zerreissung zeigt) betrifft, ist dadurch zum Verschluss gebracht, dass die Wundtlächen der Ciliarfortsätze mit dem Ligamentum pectinatum direkt verlötheten; die Ciliarfortsätze sind infolge dessen ziemlich beträchtlich nach vorne gezogen und durch zartes Gewebe in dieser Stellung fixirt.

Von diagnostischem Interesse ist der Umstand, dass ein klinisch als Irideremie imponirender Zustand sich bei der histologischen Untersuchung doch nur als eine sehr umfangreiche Iridodialyse herausstellte. Dergleichen kommt offenbar bedeutend häufiger vor, als bisher angenommen wurde und es tritt nun in einem solchen Falle immer die Frage an uns heran, (welche übrigens in klinischer Beziehung ziemlich belanglos ist, sondern nur mehr theoretisches und anatomisches Interesse hat) ob derselbe in die Rubrik der Irideremie oder der Iridodialyse einzureihen sei. Einige Beispiele aus der Literatur mögen das Gesagte beleuchten: In Arlts 2. Fall von Trideremie fand sich neben einer Skleralectasie nach oben eine Narbe innen unten in der Hornhaut, in welche die abgelöste, zu einem grauweissen Streifen geschrumpfte Iris angelöthet war. Im Falle Folkers war die Iris bis auf einen kleinen, zusammengeknäulten Rest, der in der unten in der Hornhaut gelegenen Wunde eingeklemmt war, verschwunden. In Hirschberg's Fall war von der Regenbogenhaut nur innen oben ein $3 / 4$ "' breiter Saum mit zackigen Rändem stehen geblieben, in Oellers Fall waren nach innen, wo auch die Skleralruptur lag, einzelne gezackte Reste übrig. Mc. Keown fand die Iris theilweise in der Skleral-Narbe eingeheilt, Samelson sah nur einen schmalen Saum unten, während die Skleralruptur nach oben zu gelegen war.

Zahlreicher sind die Beohachtungen, wo die Iris oder 
Theile vou ihr unter der Conjunctiva bulbi liegen geblieben waren. Es sind dies Beobachtungen von Gayet, Carré, von mir, Manolescu, Homburg, Mengin. Es ist nun möglich, dass wenigstens in einem Theile dieser, bloss klinisch beobachteten Fälle von Trideremie die Regenbogenhaut in grösserer oder geringerer Ausdehnung an ihrer Insertion noch festhielt. Besonders die zuletzt angeführten Beispiele würden den Verhältnissen des vorliegenden anatomisch untersuchten Bulbus sehr nahe kommen.

Es sei noch erwähnt, dass der Fall klinisch als wulstförmiges Intercalarstaphylom imponirte, während doch nur ein ausgedehnter Irisprolaps vorlag. Der Irrthum ist um so erklärlicher, als ja wegen der scheinbaren Trideremie eine fast vollständige Entfernung der Iris aus dem Bulbus angenommen wurde.

Schliesslich möchte ich nur noch bemerken, dass die Verïnderungen in der Hornhaut, welche das klinische Bild der" traumatischen streifenförmigen Hornhanttrübung bildeten. in vollkommenem Einklange mit den von Hess gefundenen stehen, indem nu Faltung der hinteren Horuhautlamellen und der Descemet'schen Membran, aber weder' zellige Infiltration noch Erweiterung der Saftkanälchen nachweisbar waren.

\section{Fall $\Pi$.}

Ueber denselben entnehme ich den klinischen Protocollen folgende Daten:

Johann Redl, 37 Jahre alt, Kutscher, am 26. September 1886 auf die I. Augenklinik aufgenommen. Vor ungefähr 14 Tagen fiel er mit der linken Augengegend auf eine vorspringende Kante seines Wagens auf. Er wurde bis zum Eintritt in den Krankenstand ambulatorisch behandelt.

Bei seiner Aufnahme bot der sonst gesunde Manu am linken Auge (das rechte war völlig normal) folgenden $\mathrm{Be}$ fund: Etwa $2 \mathrm{~cm}$ unterbalb des unteren Lidrandes findet sich eine $2 \mathrm{~cm}$ lange, in Verheilung begriffene, lineare horizontalverlaufende, granulirende Wunde, an deren innerem Ende die 
Haut eine röthliche, erbsengrosse, leicht fluctuirende Geschwulst bildet. Leichte Schwellung der Lider. Lichtscheu, Thränenfluss, lebhafte Ciliarinjection. Neben dem inneren Hornhautrande und mit ihm fast concentrisch verlaufend liegt in der Sklera eine von oben nach unten ziehende, etwa $1 \mathrm{~cm}$ lange, und circa $3 \mathrm{~mm}$ breite, dunkle, wulstförmige Prominenz, die gegen die Hornhaut zu ziemlich steil, sonst allmählich abfällt. Ihr oberes Drittel ist dunkelbraun, über die unteren Parthien ziehen einzelne hellgraue Stränge hinüber. Die Hornhaut queroval, matt. Aus der Tiefe der Kammer bekommt man einen dunkelrothen Reflex. Details sind absolut nicht wahrzunehmen. Die Spannung ist etwas herabgesetzt, das Auge bei Betastung schmerzhaft. Diagnose: Ruptura sclerae cum prolapsu uveae. Haemophthalmus.

Am 30. 9. 1886. Die Eetasie deutlich flacher, die Schmerzen sehr stark; daher Enucleation in Narcose. Am 14. Oktober 1886 wurde der Kranke mit reizlosem Anophthalmus entlassen.

Der in Müller'scher Flüssigkeit gehärtete und in Alkohol nachbehandelte Bulbus wurde im horizontalen Meridiane aufgeschnitten. Er zeigt normale Formen und Grössenverhältnisse. Innen an der Corneoskleralgrenze ist die Bulbuskapsel perforirt, die Rissränder stehen ungefähr $2 \mathrm{~mm}$ weit auseinander; dabei ist die hintere Wundlippe beträchtlich nach rückwärts and einwärts $d$. h. gegen die Bulbusachse verschoben. Durch diese Wunde ist eine dieselbe ganz ansfüllende, pigmentirte Gewebsmasse vorgestülpt. Die Iris fehlt vollständig, ringsum liegen die Ciliarfortsätze bloss, nur an der Ruptur ist der Ciliarkörper an der normalen Stelle nicht auffindbar, an seinem Orte liegt ein zartes unpigmentirtes weisslichgraues Häutchen, welches bis in die Nähe der Ora serrata zurückreicht. Die Linse ist im Bulbus nicht auffindbar. Von dem Prolapse spannt sich zu den gegenüberliegenden Ciliarfortsätzen eine zarte durchscheinende Membran quer vor dem Glaskörper hin. Dieser ist zu einer trüben, grösstentheils homogen aussehenden Masse geronnen. Nur im vordersten Antheile ist er mehr membranös und von streifigen und fleckigen Blutungen durchsetzt. Im hintersten Theile ist er verflüssigt und entleerte sich bei der Eröffnung des Augapfels. Netzund Aderhaut an normaler Stelle und sowie die Sklera und der Sehnervenkopf ohne makroskopisch wahrnehmbare Veränderungen. 
Die histologische Untersuchung, welche an Serienschnitten von $20-25 \mathrm{~mm}$ Dicke vorgenommen wurde, ergiebt für die Cornea ganz normale Verhältnisse. Der Kammerwinkel zeigt, abgesehen von den inneren Theilen, welche der Rupturstelle entsprechen, uberall die gleichen Veränderungen, welche den im vorigen Falle beschriebenen ausserordentlich ähnlich sind. Es fehlt nämlich die Iris vollständig ohne Hinterlassung des geringsten Stumpfes. Das Ligamentum pectinatum ist grösstentheils unverletzt, doch finden sich auch Stellen, wo die hinteren Faserzüge desselben eingerissen sind. Die Abrissstelle der Iris vom Ciliarkörper ist durch Zusammenziehung des Gewebes auf ein sehr Geringes verschmălert, ein wenig blutig imbibirt und von einem Zellenbelage überzogen, welcher vom Ligamentum pectinatum beginnt und eine Fortsetzung des Endothels der hinteren Hornhautwand zu sein scheint. Der Rissrand ist dadurch in grösster Ausdehnung geglättet, nur stellenweise etwas zackig. Der Pigmentepithelüberzug des Ciliarkörpers und seiner Fortsätze hört hier plötzlich auf, das Pigment ist stellenweise in das darunterliegende Bindegewebslager der Ciliarfortsätze verschleppt. Knapp an der Rissstelle sind einige Gefässquerschnitte sichtbar, deren Lumen vollständig verschlossen ist; dagegen ist der Circulus arteriosus iridis major an den Schnitten, an welchen er erhalten ist, (er fehlt an der grössten Anzahl der Schnitte) durchgängig. Stellenweise sind die Ciliarfortsätze nach vorne gezogen, so dass die hintere Hälfte des Ligamentum pectinatum gegen die Kammer zu von ihnen bedeckt wird. Der Ciliarkörper ist ganz normal gebildet und zeigt keine pathologischen Veränderungen. Ueber seine Oberfläche ist eine dünne Schicht von geronnenem Blute ansgebreitet, über welche ein aus einer einfachen Lage von sehr zarten Spindelzellen gebildetes Häutchen hinwegzieht.

In der inneren Peripherie des Kammerwinkels, entsprechend der Verletzungsstelle, sind die Veränderungen sehr auffallend (Fig. 16). Die Continuität der Bulbushüllen ist gerade an der Corneoskleralgrenze unterbrochen. Der Riss liegt zwar vollständig im Bereiche der Sklera, aber doch so nahe an dem Hornhautrande, dass das innere Ende desselben noch in das Ligamentum pectinatum fällt, dessen aufgefasertes peripheres Ende von der Sklera abgelöst, stellenweise mit Rundzellen und fast überall mit rothen Blutkörperchen infiltrirt erscheint. Der Schlemm'sche Canal, welcher im übrigen Umfange deutlich and 
scheinbar unverletzt nachzuweisen ist, ist an der Rupturstelle zerstört. Am cornealen Wundrande sind die Fasern sämmtlich nach auswärts gebogen, an der skleralen Wundlefze sind die inneren Faserschichten vom Wundeanal her stark in sich selbst zusammengedrückt und in steilen Wellenlinien gefaltet und nur die äusseren Faserlagen zeigen ebenfalls eine Biegung nach aussen. Wie schon bei der makroskopischen Beschreibung angegeben, ist diese sklerale Wundlippe beträchtlich nach einwärts gegen die Bulbusachse verschoben. Zwischen die Rissränder ist das Corpus ciliare eingelagert. Dasselbe ist im Bereiche der Pars plana abgerissen und weit nach vorne gezogen. An seiner Stelle befindet sich an der Innenseite der Sklera nur eine dünne Lage eines feinfaserigen und ziemlich kernreichen Bindegewebes, dessen Zellen im Allgemeinen zwar unpigmentirt sind, stellenweise jedoch einzelne Pigmentkörnchen eingelagert enthalten. Die Ränder des Risses, der unweit der Ora serrata liegt, dieselbe jedoch an keiner Stelle erreicht, verhalten sich verschieden; zumeist sind sie abgerundet, etwas gewulstet und das Pigmentepithel reicht bis knapp zu ihnen. An anderen Stellen ist jedoch der Rand wie aufgeblättert und seine inneren Schichten sind uach innen umgekrämpelt und durch feinfaseriges Gewebe gegen die Bulbusachse verzogen. Von Zonulafasern ist hier nirgends eine Spur zu finden. Die Pars ciliaris retinae ist natürlich ebenfalls durchrissen.

Der im Wundcanal der Sklera liegende Ciliarkörper ist nur dem hinteren Wundrande allenthalben innig angepresst und mit ihm verwachsen. Zwischen ihm und dem vorderen Rissrande befindet sich hingegen in ziemlicher Ausdehnung ein die ganze Dicke der harten Bulbushäute durchgreifender Spalt, welcher mit rothen Blutkörperchen angefullt ist. Doch sind die durchrissenen Faserzuge nicht dem Kammerwasser ausgesetzt, sondern werden von einer wechselnd dicken Lage von neugebildetem Bindegewebe bedeckt. Dieses tritt mit Ausnahme einer kurzen Strecke in Gestalt eines Zapfens gegen die Kammer vor und setzt sich als ein auf dem Durchschnitte als feiner Faden erscheinendes, aus zelligen Elementen zusammengesetztes, mit Blutkörperchen infiltrirtes Häutchen quer durch die Kammer nach den Ciliarfortsätzen der gegenüberliegenden Seite fort.

Der vargefallene Ciliankörper ist: stark verändert. Er ist über die innere und äussere Risskante der Sklera scharf recht- 
winkelig geknickt, mit den Ciliarfortsätzen nach aussen gekehrt. An der ersten Knickungsstelle ist er bedeutend verdinnt. Das noch intrabulbär liegende Stück desselben, welches seinem flachen Theile entspricht, ist ziemlich dünn, seine Fasern dicht aneinander gelegt und gestreckt, reichlich pigmentirt. Muskelfasern sind nicht auffindbar. Es ist zumeist des Pigmentepithels verlustig gegangen. Doch findet sich ein solches der inneren Skleralwand anliegendes Stück des Corpus ciliare nur streckenweise, an anderen Stellen ist es vollständig durch den Wundschlitz hindurch getreten oder mit einem mehr minder beträchtlichen Antheil noch in demselben eingeklemmt. $\mathrm{Es}_{\mathrm{s}}$ ist sehr stark deformirt, seine Muskulatur hochgradig atrophisch. Die Ciliarfortsätze sind verbogen, zusammengedrückt, nach aussen gekehrt d. h. von der Sklera abgewendet, etliche blutig imbibirt. Ihr epithelialer Ueberzug ist grösstentbeils gut erhalten, stellenweise jedoch ist die unpigmentirte Zellenlage von der pigmentfubrenden abgehoben und bildet derart cystische Räume; an anderen Stellen hinwiederum ist sie gewuchert, die Zellen fast spindolig ausgewachsen. Wieder an anderen Stellen sind beide Zelllagen verloren gegangen und das retinale Pigment in das umgebende junge Narben-Gewebe verschloppt. Streckenweise ist die Grenze zwischen diesem und dem Stroma des Ciliarkörpers völlig verwiseht und unkenutlich geworden.

Die Bindehaut ist entsprechend dem Prolaps vorgebaucht, ihr Epithel von gewöhnlichem Aussehen. Dasselbe sendet an einer Stelle einen hohlen Zapfen in die Tiefe, welcher dio Fortsätze des vorgefallenen Ciliarkörpers erreicht. An deren Oberfäche breitet sich das Epithel aus und umschliesst mehrere flache Hohlräume, welche durch den erwäbnten Fistelgang mit der Oberfläche in Verbindung stehen. Diese Räume sind zum Theile leer, enge, mit einander berübrenden Wandungen, zum Theile enthalten sie pigmentgeschwängerte Rundzellen und grössere, bläschenartige, doppeltcontourirte Gebilde, welche entweder Degenerationsformen von Epithelzellen oder aber Parasiten darstellen, wie ich sie gelegentlich in einem Falle von Pigmentirung der Bindehaut fand. Dieselben wurden auch von Fuchs in Präparaten von Pterygien vorgefunden und beschrieben.

Die Bindehaut ist ödematös, vou zahlreichen Rundzellen durchsetzt, welche zu kleinen Heerden besonders in dex Umgebung der beträchtlich erweiterten und sebr zahlreichen Ge- 
fässe zusammentreten. Ausserdem finden sich auch hier in ausserordentlich reichlichem Maasse die im vorigen Falle aus. führlich beschriebenen Pigmentablagerungen in den Rundzellen, Bindegewebszellen und in den perivaseulären Lymphscheiden vor.

Wenn man die Verwundungsstelle nach oben zu gegen ihr Ende hin verfolgt, so findet man vorerst, dass der Ciliarkörper hier wieder in ganzer Ausdehnung von dem retinalen Blatte überzogen ist. Der intrabulbäre Antheil wird grösser, wodurch die Rissränder in der Pars plana näher an einanderrücken. Das extrabulbär gelegene stück des Ciliarkörpers zieht sich allmählich zurück, bis sich zuletzt der Vorfall nur mehr auf ein paar Ciliarfortsätze beschränkt. In gleichem Maasse rücken die skleralen Wundränder aneinander und erreichen sich endlich; doch hat hier die Verheilung durch reichliches Narbengewebe mit einer Stufenbildung stattgefunden, da, wie schon oben erwähnt, die hintere Wundlippe gegen das Bulbusinnere verschoben ist. Der Ciliarkörper gewimnt, nachdem er ganz aus dem Wundspalte zurückgetreten ist, annäherud normale Gestalt, auch seine Muskulatur ist hier nicht mehr so hochgradig atrophisch. Allein obwohl er an normaler Stelle liegt, ist er selbst an Schnitten, wo von einem Skleralriss nichts mehr wahrzunehmen ist, noch nicht an der Corneoskleralgrenze angewachsen. Die Trennung im Bereiche der Pars plana ist hier weiter nach vorne verschoben und geht quer durch die Muskulatur des Ciliarkörpers.

Verfolgt man den Riss der Bulbushüllen weiter nach unten $z u$, so findet man den der Sklera durch eine ungefähr $1 \mathrm{~mm}$ breite Narbenmasse verschlossen, an welche die Ciliarfortsătze angewachsen sind und von welcher ein zapfenartiges Gebilde in den Kammerraum vorspringt. An diesen setzt sich die schon erwähnte nach der gegenüberliegenden Seite ziehende Mernbran an.

Weiter nach abwärts stellt sich die Continuität der äusseren Lederhautschichten wieder her, während die klaffende Berstung der inneren durch Narbengewebe ausgefullt ist. Auch hier ist der Ciliarkörper voch nicht dureh die Sehne des Musculus eiliaris an die Sklera angeheftet, liegt jedoch an gewöhnlicher Stelle. Die Ciliarfortsätze sind durch Blutaustritte gebliht, ihr Pigment- and Epithelüberzug zerworfen. Erst in den Parthien, wo die Sklera ganz unverletzt erscheint, ist die normale Fixation des Ciliarkörpers erhalten. In dem 
Beiträge zur patholog. Anatomie d. traumatischen Aniridie etc. 17

ganzen Bereiche der unteren Hälfte der Skleralruptur ist das Corpus ciliare von der Chorioidea nicht abgerissen.

Sowohl von der Linse als von ihrer Kapsel sind keine Reste auffindbar. Dagegen sind die Zonulafasern mit Ausnahme der schon erwähnten Stelle allenthalben von der Ora serrata bis zu den Spitzen der Ciliarfortsätze zu verfolgen und zwischen ihnen Blatkörperchen in reichlicher Menge angesammelt.

Der Glaskörper, welcher durch die von dem Prolapse zu dem Kammerwinkel der gegenüberliegenden Seite ausgespannte Membran nach vorne abgeschlossen wird, ist membranös degenerirt, von Blutaustritten verschiedener Grösse durchsetzt. Ebenso finden sich in der vorderen Kammer, besonders gegen die Kammerbucht zu, Anhäufungen von gut erhaltenen rothen Blutkörperchen.

Die Retina zeigt ausser einer Höhlen- und Lückenbildung in ihren inneren Schichten nahe der Ora serrata keine pathologischen Veränderungen. Die Chorioidea ist blutreich, ohne Entzündungsheerde. Im Sehnervenkopf findet sich ganz geringe Kernvermehrung.

Eine Zusammenfassung vorstehender Befunde ergiebt eine Berstung der Sklera nahe an der inneren Grenze der Hormhaut mit Zerstörung des Schlemm'schen Canales. Durch die weit klaffende Lücke ist der Ciliarkörper vorgefallen, welcher sowohl nahe der Ora serrata quer durchrissen als auch von seiner vorderen Insertion an der Corneoskleralgrenze abgetrennt ist. Doch ist nicht allenthalben eine Verwachsung des prolabirten Theiles mit den Wundrändern erfolgt, sourdern es hlieb zwischen Ciliarkörper und cornealer Wundlefze eine von neugebildetem Gewebe (Narbengewebe) ausgekleidete Spalte bestehen. Aehnliches junges Gewebe überzieht, von der Conjunctiva bedeckt, den ganzen Prolaps. Sowohl hier, als auch sonst im ganzen Umfange fehlt die Iris vollständig. Kein woch so kurzer Stumpf ist auffindbar. Die Veränderungen im Kammerwinkel (mit Ausnahme der Rupturstelle) entsprechen vollkommen denen im vorigen Falle und bestehen in einex direkten Anwachsung der Ciliarfortsätze an das Iigamen- 
tum pectinatum ohne Einschaltung einer nennenswerthen Narbenmasse. - Die Linse fehlt spurlos. Sie ist jedenfalls durch die Skleralwunde aus dem Bulbus ausgetreten und durch einen Riss in der Bindehaut gänzlich verloren gegangen. Als Ueberrest dieser letzteren Verletzung findet sich noch der von Bindehautepithel ausgekleidete und bis auf den prolabirten Ciliarkörper reichende Fistelcanal, der sich in der Tiefe zu flachen Hohlräumen ausweitet.

Was die Ausdehnung des Risses anbelangt, so nimmt er in der Lederhaut ungetähr ein Viertel des Umkreises ein; in der Pars plana corporis ciliaris ist derselbe nach oben bedeutend ausgedehnter, so dass auf Schnitten im imneren oberen Quadranten, welche schon eine unverletzte Sklera zeigen, der Riss im Strahlenkörper noch weit klafft. Nach unten zn kehrt sich dieses Verhältniss um, so dass die Trennung in der Sklera weiter nach abwärts reicht als die des Corpus ciliare. Wie selbstverständlich, erstreckt sich auch die Abtremnung des Ciliarmuskels von der Sklera beträchtlich weiter als der Prolaps; deun nur, wenn die Lockerung des Ciliarkörpers genügende Ausdehnung erreicht hatte, konnte ja derselbe vorfallen. Dieser Fall ist besonders ron Interesse, werm man ihn mit dem vorigen zusammenhält, mit welchem er weitgehende Aehnlichkeit in der klinischen Erscheinung und selbst im makroskopischen Aussehen des hemisecirten Bulbus besitzt. In beiden Fällen besteht nämlich eine Ruptur der Lederhaut mit Vorfall der Uvea, traumatische Aniridie und Aphakie und blutige Durchtränkung des Glaskörpers. Während aber im ersten Falle der Prolaps durch vorgestuilpte Tris gebildet ist, besteht er in diesem aus dem vorgefallenen Strahlenkörper bei totalem Defecte der Regenbogenhaut. Es ist also gewiss nöthig, hier einen anderen Vorgang bei der Verletzung anzunehmen als im vorigen Falle. Ist es ja doch sehr auffallend, dass bei völligem Mangel der Tris ein Vorfall des Ciliarkörpers in einer Gegend zustande kam, 
Beiträge zux patholog. Anatomie d. tranmatisehen Aniridie etc. 19

welche vor seinem Ansatze gelegen ist. Ueberhaupt müssen bei der Entstehung eines Ciliarkörpervorfalles ganz andere Kräfte in Action treten als bei der eines Trisprolapses, zu dessen Bildung schon der Druck des aus der hinteren Kammer vorstürzenden Kammerwassers allein vollkommen hinreicht.

Hier lassen sich zwei Möglichkeiten des Verletzungsmechanismus in Erwägung ziehen. Erstens ist es denkbar, dass durch die Skleralruptur die Iris vorfiel während sie ähnlich wie im vorigen Falle, noch im Zusammenhange mit dem Ciliarkörper stand und dass sie dann erst so brüske abgerissen wurde, dass hierdurch derselbe sowohl von der Sklera abgesprengt, als auch nahe der Ora serrata durchrissen wurde und durch den Skleralspalt vorfiel. Dieser Verletzungsmechanismus ist mir aber nicht sehr wahrscheinlich, weil die Insertion der Regenbogenhaut an den Ciliarkörper recht ungünstig gelegen ist, um einen Prolaps des letzteren durch einfachen $Z u g$ zu erzeugen. Ausserdem widerspricht dem auch die hundertfältige Erfahrung, dass sich die Iris verhältuissmässig leicht vom Corpus ciliare abtrennen lässt, während doch die Anheftung des Musculus ciliaris an die Sklera eine sehr feste, sehnige ist.

Die zweite Möglichkeit scheint mir mehr für sich zu haben. Es dürfte nämlich in gewöhnlicher Weise (welche wir allerdings nicht näher kennen) durch Einwirkung der stumpfen Gewalt gleichzeitig mit der Bulbusberstung oder richtiger noch vor derselben eine totale ringförmige Ablösung der Iris entstanden sein und dieselbe durch die Wunde in der Lederhaut aus dem Augapfel hinausgeschwemmt worden sein. Die Abtrennung und der Vorfall des Ciliarkörpers erfolgte dann unabhängig von der Iridodialyse durch Einwirkung der luxirten Linse, welche ebenfalls durch die Skleralwunde aus dem Bulbus auszutreten versuchte, hierbei aber mit ihrem Aequator sich gegen die Ciliarfortsätze und den Ciliarkörper stemmte und so dieselben vor sich 
herdrängte und einerseits von der Sklerotica, andererseits von der Chorioidea abriss und durch den Schlitz in der Sklera hinausstülpte. Gleichzeitig wird auch der Druck des Glaskörpers gegen die Wundöffnung sowohl direkt auf den Ciliarkörper gewirkt als auch den von der Linse auf denselben ausgeiibten Druck verstärkt haben. Möglicherweise kann dabei auch eine abnorme Festigkeit der Zonula Zinnii mitgeholfen haben, welche hinderte, dass sich die Linse frithzeitig aus allen Verbindungen löste und vor den Ciliarkörper trat. Das vorgefallene Corpus ciliare wurde offenbar durch die nach dem Abfluss des Kammerwassers und dem Austritte der Iinse sich aneinanderlegenden Wundränder der Lederhant eingeklemmt, incarcerirt und so lange festgehalten, bis sich Verwachsungen mit der Umgebung ausbildeten und die weitere, definitive Fixirung übernahmen.

\section{Fall III.}

Schiessbuhl, Johann, Wirthschaftsbesitzer, 37 Jahre alt, aufgenommen am 8. Sept. 1892 sub Journal-Nr. 17043 auf Z.-Nr. $57^{\mathrm{b}}$ der I. Augenklinik.

Am 8. September Nachmittags wurde er von einem Freunde auf der Rebhühnerjagd angeblich aus einer Entfernung von ungefähr 100 Schritten (mit Schrot Nr. 12) angeschossen. Er verspürte augenblicklich starken Schmerz im rechten Auge, welches von dem Augenblicke an blind war und heftig blutete. Er fuhr sogleich nach Wien in die Klinik, wo ich ihn ungefähr 5 Stunden nach den Unfalle zu sehen bekam.

Er zeigte mehrere Schussverletzungen am Körper, nämlich an der rechten Wange $2 \mathrm{~cm}$ unterhalb des unteren Orbitalrandes; an der Mitte der Stirne; an der rechten Seite der Oberlippe, welche perforirt war und der eine Quetschung am Zahnfleische des rechten oberen Eckzahnes entsprach; an der rechten Halsseite, am rechten Handrücken; am rechten Oberarme. Fast an allen diesen Stellen liess sich unter der Haut das Schrotkorn tasten.

Das rechte Auge zeigte folgende Verletzungen: In dor Mitte des unteren Lides, knapp unterhalb der Cilienreihe be- 
Beiträge zur patholog. Anatomie d. traumatischen Aniridie etc. 21

findet sich eine mit vertrocknetem Blute bedeckte, unregelmässige, zackigrandige Wunde von ca. $3 \mathrm{~mm}$ Durchmesser, welche die ganze Dicke des Lides durchsetzt und der an der conjunctivalen Seite eine ähnliche zackige Wunde entspricht. Die Bindehaut ist sonst blass; am Bulbus ein ganz zarter, die Hornhaut umgebender episkleraler Injectionsring. Unmittelbar unter dem Hornhautrande befindet sich eine die Conjunctiva und Sklera durchdringende, sternförmige Oeffunng, aus welcher dickflüssiges, dunkles Blut austritt. Alle droi erwähnten Oeffnungen in Lid und Sklera entsprechen der Lage nach einander genau und haben den gleichen Durchmesser.

Hornhaut klar, normal, Vorderkammer aufgehoben; von dex Iris ist keine Spur zu sehen. Die Linse ist klar and zeigt nur an ihrer vorderen Kapsel zwei kleine gelbliche Fleckchen. Hinter der linse erscheint bei seitlicher Beleuchtung ein hellblutrother Reflex. Fundus nicht sichtbar. Der Patient nimmt mit diesem Auge eine Kerzenflamme in unmittelbarer Nähe nur undeutlich wahr.

Das linke Auge ist normal gebildet und ohne pathologisehe Veränderung $V=6 / 6$.

Die Diagnose lautete: Vulnus sklopetarium palpebrae in. ferioris et sclerae o. d. Haemophthalmas. Aniridia traumatica. Doch musste auch die Möglichkeit in Betracht gezogen werden, dass statt eines völligen Mangels nur eine Einsenkung der Iris hinter die Linse vorliegen könne; denn die Untersuchung im durchfallenden Lichte, welche Aufschluss hätte bieten können, war, wie erwähnt, wegen Glaskörperblutung nicht durchführbar.

Ich verordnete dem Kranken warme Ueberschläge, Bettruhe und täglich 2 malige Einträufelung von 1 Tropfen einer $1 \%$ Atropinlösung.

Am 9. September hatte die Injection zugenommen. Starke Schmerzhaftigkeit. Am 10. IX. 92. Die Cornea gestichelt, in ihren hinteren Schichten diffus getrübt, so dass dio tieferen Theile kaum sichtbar sind. Therapie: Verband mit essigsaurer Thonerde, $3 \mathrm{mal}$ täglich warme Ueberschläge, sonst wie früher. Heftige spontane Schmerzen im Auge, wobei der Kranke das Gefühl angiebt, ,als ob das Schrotkorn im Bulbus hin und her rollon würde". Am 12. IX. 92. Die Hornhauttrübung und Stichelung hat noch zugenommen. Die Kammer hat sich wieder hergestellt, ihre innere Hälfte ist mit dunklem Blute erfüllt. (Der Kranke liegt auf der linken Seite.) 
Da angenommen werden musste, dass das Projectil sich noch im Bulbus befinde und die Gefahr einer sympathischen Ophthalmie nahe lag, wurde am 12. Sept. 92 die Enucleation in Chloroformnarkose vorgenommen, wobei es gelang, den durch die Schusswunde am unteren Limbus drohenden Glaskörpervorfall za vermeiden. Der weitere Verlauf war normal. Pat. wurde am 18. IX. mit reizlosem Anophthalmus aus der Anstalt entlassen.

Der Bulbus wurde sogleich in Müller'sche Flüssigkeit gebracht, wo er durch 2 Monate verweilte, dann ausgewässert und in Alkohol von steigender Concentration nachgehärtet. Er wurde im verticalen Meridian halbirt, so dass der Schnitt durch den Schusscanal ging, dann jede Hälfte in Celloidin eingebettet, in Serien geschnitten und gefärbt. Zur Anwendung gelangten: Haematoxylin (Böhmer) und Eosin, Lithioncarmin und Picrinsäure oder Anilinblau, Bismarekbraun.

Die makroskopische Untersuchung ergab normale Maasse des Bulbus. Unten an der Corneoskleralgrenze, aber schon der Sklera angehörend, befindet sich eine dieselbe in der Richtung von vorne nach hinten horizontal durchdringende, etwas über $1 \mathrm{~mm}$ weite canalartige Oeffnung, in deren Umgebung die Bindehaut wulstig aufgeworfen ist, und welche von einer rothbraunen Masse erfüllt wird, die sich in gleichgefärbte, theils lamellär angeordnete, theils mehr klumpige Massen in der vorderen Glaskörpergegend fortsetzt. Die Hormhaul zeigt keine sichtbaren Veränderungen, die vordere Kammer ist mit theils gelblichweissen fädigen und membranartigen, theils blutig imbibirten Gerinnseln erfüllt. Die Linse ist um ein geringes nach vorne gerückt, so dass die Kammer verengt wird, und gleichzeitig nach oben verschoben, so dass der Linsenrand an den Ciliarfortsätzen anliegt. In den unteren Parthien der Linse fehlt die geschichtete Structur. Die Iris mangelt vollständig. Der Ciliarkörper ist an der dem Einschusse entsprechenden Parthie von der skleralen Fixation gelöst und nach rückwärts dislocirt.

Die Netzhaut ist in grosser Ausdehnung besonders nach unten $\mathrm{zu}$ weit von der Chorioidea durch einen massigen geronnenen Bluterguss abgehoben, der Glaskörperraum dadurch bedeutend verengt und von einem Fachwerke von Gerinnseln erfült, welches nach vorne und unten in die bereits erwähnten Blutgerinnsel übergeht. Auch die Aderhaut ist im ganzen Umfange flach abgehoben. Der Sehnerv zeigt nichts Besonderes. 
Mikroskopische Untersuchung: (Figur 6.) Die Hornhaut ist von gewöhnlicher Dicke und Wölbung, ihr Epithel grösstentheils normal; nur in der unteren Hälfte der Cornea sind die oberflächlichen Epithelschichten stellenweise ausgefallen, so dass nur die Basalzellen mehr vorhanden sind; streckenweise, jedoch nur in sehr geringer Ausdehnung, fehlen auch diese, so dass die sonst normale Bowman'sche Membran blossliegt. Das Hormhautgewebe ist im Allgemeinen etwas kernreicher, die Lamellen in den hinteren Schichten dureh Verbreiterung der $Z$ wischenränme lockerer gefügt, auseinandergedrängt.

In den interlamellären Räumen besonders der unteren Cornealhälfte finden sich zahlreiche Rundzellen eingelagert, welche im Durchschnitt spindelförmig gestaltete Gruppen bilden. Zwischen der Lamina Descemetii und den hinteren Hornhautlamellen werden diese Heerde bedeutend mächtiger und Hiessen za einer ununterbrochenen Schicht von Wanderzellen zusammen.

Die Descemet'sche Haut ist grob gewellt. An dieser Faltung nehmen auch die Hornhautlamellen im ganzen hinteren Drittel der Dicke in abnehmender Intensität Theil, indem sich die Wellen, je weiter man nach vorne kommt, immer mehr abflachen und schliesslich ganz verstreichen. Das Endothel ist auf kurzen Strecken abgestossen und hier kleben rothe Blutkörperchen direkt an der Descemet'schen Membran, an anderen Stellen mittelst zarten Fibringerinnseln an dem Endothel.

Das Stückchen Bindehaut, welches am Bulbus bei der Enucleation erhalten blieb, ist bis auf eine ziemlich beträchtliche Hyperaemie normal. Nur in der Umgebung des Einschusses ist sie stärker gewulstet, mit Fibrinnetzen und rothen Blutkörperchen durchsetzt. An einer ganz beschränkten Stelle ist sie völlig durchrissen, die Wundränder eingerollt und blutig imbibirt; das in Wucherung begriffene Epithel dringt ein kurzes Stück weit in den Wundtrichter hinein vor. Aus demselben quillt in Gestalt eines Zapfens Glaskörpergewebe vor.

Die Schussoffnung liegt knapp neben dem Limbus corneae, gehört aber schon vollständig der Sklera an, so dass weder die Bowman'sche noch die Descemet'sche Haut verletzt sind. Das Ligamentum pectinatum ist jedoch zerrissen und seine durchtrennten Fasern sind in den Schusscanal eingestülpt. Die skleralen Wundränder zeigen eine Abrundung, indem die äussersten und innersten Schichten der Lederhaut gegen die 
Lichtung des Schusscanales eingerollt sind. Von hier angefangen und bis über die Ansatzstelle des Musculus rectus inferior hinausreichend, ist die Sklerotica theils mit rothen Blutkörperchen, theils mit Wanderzellen infiltrirt; das Gleiche gilt von dem episkleralen Bindegewebe.

Der in der Schusswunde liegende Glaskörper ist reichlich mit rothen Blutzellen durchsetzt, ausserdem aber auch woch von Leucocyten, welche in Zügen angeordnet und streckenweise mit grobkörnigem, dunkelbraunem Pigment angefüllt sind. Einzelne Pigmentkörnchen finden sich hier auch frei, ebenso wie in dem Gewebe der Sklera selbst längs der Rissränder. An einigen Schnitten sind letztere sogar eine Strecke weit von einer continuirlichen Lage von pigmentfübrenden Zellen, welche vollständig denen des retinalen Pigmentblattes der Iris gleichen, überkleidet.

Es handelt sich hier offenbar um abgestreiftes Iristapet und dies ist der einzige Rest der Regenbogenhaut, weleher im ganzen Bulbus aufzufinden ist.

Die Verhältnisse des Kammerwinkels gestalten sich folgendermassen:

An der Einschussstelle ist, wie schon erwähnt, das Ligamentum pectinatum durchrissen, die Rissräuder in den Wundcanal eingeschlagen. Die Verletzung trifft auch den Ansatz des Corpus ciliare. Dasselbe ist vollständig ron seiner skleralen Insertion abgelöst, ein Stück weit nach rückwärts gerutscht und reichlich mit Blut imbibirt, welehes alle Spalten zwischen dem Netzwerk des Ciliarmuskels und die ganzen Ciliarfortsätze soweit sie erhalten sind, erfült. An circumskripter Stelle ist die ganze vordere Hälfte des Ciliarkörpers sammt seinen Fortsätzen zerstört, an seiner Stelle eine aus Glaskörper, Fibringerinuseln und Blutkörperchen zusammengesetzte Masse; in dieser befindet sich ein aus Leucocyten bestehender, scharf umschriebener Heerd, in dessen. Mitte der Querschnitt eines Haares eingebettet liegt. Riesenzellen sind nicht vorhanden. Das Haar hat nicht auf allen Schnitten die gleiche Lage. Denn nur in den der Mitte der Perforationsöffnung entsprechenden Schnitten nimmt es den eben beschriebenen Ort ein; in den weiter nach innen zu gelegenen Schnitten rückt es allmählig weiter nach rückwärts, so dass es dann an die Innenseite des abgetrennten Ciliarkörpers bis hinter die Urspruugsstelle der Ciliarfortsätze zu liegen kommt. Es ist weder die Spitze des Haares, noch die Wurzel, oder 
Haarzwiebel vorhanden; es bandelt sich also um ein kurzes Stück mitten aus einem Haare, welches seiner Stärke nach einer Cilie entspricht.

An den von der Einschussöffinung mehr weniger weit entfernten Theilen sind die anatomischen Verhältnisse des Kammerwinkels ungleich interessanter und wichtiger und fast im ganzen Umfange von dem gleichen Wesen. Vorerst fehlt die Iris vollständig; es ist auch nicht der allergeringste Rest von ihr an der Ansatzstelle zurückgeblieben. Die Gegend, wo sie sass, ist durch eine tiefe, in den vorderen Theil des Ciliarkörpers eindringende, die Vorderfläche des Musculus ciliaris vollständig blosslegende Höhle eingenommen. Es ergiebt sich demnach, dass die Regenbogenhaut nicht an ihrer Wurzel abgerissen, sondern aus dem Strahlenkörper herausgerissen ist. Die genauere Begrenzung der erwähnten Höhle (Fig. 7) wird gebildet: nach vorne von dem Ligamentum pectinatum welches fast au keiner Stelle unversehrt geblieben ist, sondern dessen Balkenwerk streckenweise selbst in ganzer Dicke eingerissen ist. Die einzelnen Bälkchen stehen sparrig auseinander. Ihre Zwischenräume sind erfüllt mit rothen Blutkörperchen, welche offenbar aus dem Schlemm'schen Canale stammen, da derselbe an seiner Hinterwand stellenweise eröffnet ist (Fig. 7). Nach hinten begrenzt sich der Hohlraum durch die Fasern des blossgelegten Ciliarmuskels, welche streckenweise zwischen sich pigmentführende Zellen tragen; gegen die Bulbusachse zu wird die Grenze gegeben durch die Rissräuder der Ciliarfortsätze und durch die zum Theile erhaltenen, zum Theile aber auch zerrissenen und durch frische Thromben verschlossenen Gefässchen, welche Aeste des Circulus arteriosus iridis major darstellen. Dieser selbst lässt sich nur streckenweise nachweisen, streckenweise fehlt er und die Stelle, wo er liegen sollte, făllt in den mehrfach erwähnten Hohlraum, der durch das Herausreissen der Iris entstanden ist. Die Ciliarfortsätze sind alle ziemlich weit gegen die Hornhaut vorgerückt, so dass die Höhlung noch tiefer erscheint. Einige zeigen dabei die Neiguug sich mit ihrem Rissrande gegen dieselbe hin einzurollen. Die Rissstellen sind nur sehr wenig blatig suffundirt und zeigen keine entzündlicben Teränderungen. Auch das Epithel der Ciliarfortsätze hat keine Wucherungstendenz. Ausser dem Beginne einer hyalinen Degeneration im Halstheile welche ja als seniler Vorgang aufzufassen ist, zeigen die Ciliarfortsätze keinerlei pathologische Veränderung. 
Die übrigen Befunde an dem Auge seien nur ganz kurz angeführt:

Die Linse, welche etwas nach oben verschoben ist, so dass sie dort an die Ciliarfortsätze anstösst, zeigt eine Eröffnung ihrer Kapsel in der Aequatorgegend entsprechend der Schusswunde. Die Wunde klafft weit, ihre Rissränder sind nur wenig nach aussen umgekrämpt. Die äquatorialen Parthien der Linsenrinde sind kataraktös zerfallen und in Form einer den sklerosirten Kern bis zur hinteren Polgegend umgreifenden Schale von Rundzellen infiltrirt. Die hintere Capsel ist auffallend dünn und am hinteren Pole von der Linse abgehoben. Hier befinden sich zahlreiche kleinere und grössere Blasen in deu subcapsulären Rindenschichten; ähnliche ringsum in der Kernbogengegend. Die Zonulafasern sind oben und natürlich anch unten zerrissen, an den seitlich geführten Schnitten jedoch wohl erhalten.

Der Kammerraum ist von einem dichten Fachwerk von zierlichen Fibringerinnseln ausgefüllt, welches innig an der vorderen Linsenkapsel haftet und seinen Ursprung aus dem Kammerwinkel nimmt. Es ist reichlich mit rothen Blutkörperchen durchsetzt und enthält auch in den der Linse unmittelbar anliegenden Antheilen grössere Fibrinklumpen und kleine Nester von Leukocyten. Gegen den Boden der Kammer wird die Blutansammlung am mächtigsten.

Der Glaskör per ist zerklüftet, sehr zellreich und von Blutaustritten in welehselnder Grösse durchsetzt; in den hinteren unteren Parthien ist er dureh einen grossen Blutklumpen ganz verdrängt. Zerstreut finden sich grössere und kleinere Heerde von Rundzellen. Ciliarkörper und Chorioidea sind von der Sklera flach abgehoben, die Netzhaut von der Ora serrata an abgelöst. Ihr unterer Theil zieht senkrecht gegen die Bulbusachse bis hinter den hinteren Linsenpol und biegt erst hier nach rückwärts um. Der subretinale Raum wird theils durch Blut, theils durch feinkörnig geronnene, mit Eosin färbbare Massen ausgefüllt. Die Retina ist in ihren Schichten ganz gut erhalten, bietet keine Zeichen von Entzündung.

Unterhalb des Sehnervenkopfes, welcher ausser einer geringen Kernvermehrung keine Veränderungen zeigt, befindet sich eine Perforation der Netzhaut, Ader- und Lederhaut. An letzterer ist die Wundöffnung von dem gleichen Caliber win vorne an der Corneoskleralgrenze; nur sind hier die Wundränder nach aussen gerollt und zwar sowohl die inneren als 
Beiträge zur patholog. Anatomie d. traumatischen Aniridie etc. 27

auch die äusseren Rändor des Canales, welcher dadurch die Form eines mit der Basis dem Bulbusinneren zugewendeten Trichters erhält. Die Rissränder der Chorioidea sind weit zurückgezogen, gewulstet und nur wenig eingerollt, zellig und insbesondere blutig infiltrirt, liegen aber der Sklera an. Die Netzhaut hat sich nur um ein geringes weiter als die Aderhaut retrahirt und ist von Blutaustritten gesprenkelt. In ziemlicher Ausdehnung haben sich hier die Aussenglieder der Stäbchen und Zapfen von den übrigen Netzhautschichten in Gestalt einer zusammenhängenden, gefalteten Membran abgelöst; diese liegt nun zwischen Pigmentepithel und Netzhaut in Blutcoagula eingebettet und steht mit ihrem Rande noch mit der Stäbchenzapfenschichte im festem Zusammenhange.

Die Ciliarnerven sind von entzüudlichen Veränderungen frei. -

Die makroskopische und insbesondere histologische Untersuchung ergiebt also ausser den für die Frage nach der Irideremie und Iridodialyse in Betracht kommenden Veränderungen noch eine Reihe von Befunden, welche zuerst in Küxze besprochen werden mögen.

Zuerst ist herrorzuheben, dass das Schrotkorn nicht, wie angenommen worden war, noch im Bulbus verweilte, sondern unterhalb des Sehnerveneintrittes die Augenmembranen zum zweiten Male perforirt hatte und in das Orbitalgewebe eingedrungen war. A uf seinem Wege durch das Lid hatte es eine Cilie mitgerissen und in das Innere des Augapfels verschleppt, wo sie liegen blieb, jedoch nicht ohne eine entzündliche Reaction in ihrer Ungebung hervorzuruten ${ }^{1}$ ). Zugleich wurde der vordere Theil des Ciliarkörpers zerstört, die Linsenkapsel in der Aequatorgegend zum Bersten gebracht, die Linse subluxirt, die Netzhaut durch Bluterguss abgehoben. Die Hornhaut zeigt das typische Bild der interstitiellen Entziundung.

1) Ein ähnlicher Befund wurde von Deutschmann gelegentlich gemacht, doch fanden sich dort in der Umgebung der Cilie auch Riesenzellen, welche in unserem Falle fehlen, offenbar weil die Zeit (4 Tage) noch zu kurz zu ihrem Auftreten war. 
Für die Beurtheilung der Veränderungen im Kammerwinkel bei Irideremie ist der vorliegende Fall deshalb von hervorragender Wichtigkeit, da die Enucleation schon am 4. Tage nach der Verletzung vorgenommen wurde, die ursprünglichen Wundverhältnisse also durch secundäre Veränderungen noch relativ wenig alterirt oder verwischt worden waren.

Wie in dem vorigen Falle ist die Iris ganz glatt von ihrem Ansatze abgetrennt und zwar sammt einem geringen Antheil aus den vordersten Parthien des Ciliarkörpers. Hierbei ist das Ligamentum pectinatum allenthalben eingerissen, an manchen Stellen anch noch die Hinterwand des Schlemm'schen Canales durchbrochen, so dass sich dessen Inhalt frei in die Kammer ergiessen konnte. Der Circulus arteriosus iridis major ist stellenweise ganz zerstört, sonst sind die von ihm abgehenden Aeste knapp au ihrem Ursprung ab- oder ausgerissen, der Ciliarmuskel vorne.vollständig entblösst, aber nur wenig blutig infiltrirt.

Von der Iris ist als einzige Spur beträchtliche Pigmentirung in einer Strecke des Schusscanales aufzufinden und dies giebt einen Hinweis auf den Mechanismus der Verletzung und den Zeitpunkt der Irisabtrennung. Meiner Ansicht nach erfolgte die Iridodialyse schon zu einer Zeit, als die Skleralperforation noch nicht vollendet war; vielleicht sogar schon in dem Augenblicke als das Schrotkorn auf das untere Lid aufschlug und so, da sich jetzt der Anprall auf eine grosse Fläche verbreitete, als stumpfe Gewalt wirkte. Die ringsum abgetrennte und zu einem kleinen Klümpchen zusammengeballte Tris wurde, sobald das Schrot die Sklera völlig durchsetzt hatte und das Loch klaffte, von dem Strome des durch die enge Oeffnung hervorsturzenden Kammerwassers erfasst und aus dem Bulbus hinausgeschwemmt, wobei sich ihr Pigment an dem Wundcanal theilweise abstreifte.

Dieser Fall scheint mir direkt gegen die Ansicht 
Manolescu's über die Entstehung der Irideremie zu sprechen. Nach derselben ist das erste immer eine Perforation der Bulbuskapsel, das zweite ein Trisprolaps und dann übernimmt das Kammerwasser die Hauptrolle, indem es wegen seiner Incompressibilität die vorgestülpte Tris ringsum abreisst und mit schwemmt ${ }^{1}$ ).

Später, d. h. nachdem das Schrotkorn schon durch die Lederhaut hindurchgedrungen und die offene Lücke in derselben entstanden war, konnte meines Erachtens keine Irideremie mehr entstehen, da das Kammerwasser sowohl vor der Iris aus der vorderen Kammer, als durch das entstandene Loch in derselben aus der hinteren Kammer frei hätte abfliessen können, also kaum Gelegenheit zu einem Irisprolapse geschweige denn zu einer vollständigen $\mathbf{A b}$ reissung und Hinausschwemmung der Iris vorhanden gewesen wäre.

Es sei noch der relativen Seltenheit von Irideremia traumatica mit Erhaltung der Linse Erwähnung gethan. Am seltensten sind wohl die Fälle, wo die Linse weder ihre Lage änderte noch sich trübte. Hierher gehören Beobachtungen von Chisolm, Folker, Argyll Robertson, Hjort, Lange, Gayet, Carré, von mir, Hirschberg, Arlt ${ }^{2}$. Bedeutend häufiger sind die Fälle wo eine gleichzeitige Luxation der Linse stattfand entweder iu den Glaskörper

1) Ausserdem sprechen gegen diese Theorie (oder wenigstens gegen ihre allgemeine Annahme) alle Fäle, wo keine Perforation stattfand (z. B. Schäfer, 3. Fall) und alle die, wo die abgerissene und zusammengeknäulte Iris am Boden der Vorderkammer aufgefunden wurde (z. B. Schaligin, Fischer).

2) Die Fälle von Graefe, Rau, Weller, Heyfelder, Mooren dürfen nicht hierher gereehnet werden, da in denselben die durch eine Hornhautwunde vorgefallene Iris artificiell entweder absichtlich oder durch Ungeschicklichkeit der hülfeleistenden Person herausgerissen worden war. Im Falle $O$ Glesbys wurde bei einer Kataraktextraction in einem sonst ganz normalen Auge mit prompt reagirender Pupille die ganze Iris herausgezogen. Da dies ohne Blutung stattfand, kommt 
(z. B. Schaligin, Armaignac, Öttingen, Galezowski) oder unter die Bindehaut (z. B. Oeller, Homburg, Mengin). Diese letzteren geben den Uebergang zu dem häufigsten Vorkommniss, dass nämlich die Linse vollständig fehlte, indem sie zumeist durch eine Skleralruptur unter gleichzeitiger Zerreissung der Conjunctiva den Bulbus ganz verlassen hatte (z. B. Jeaffreson, Samelson, Krajewski, Schiess-Gemuseus, Dixon, Samelson, Manolescu, Nunnely, Williams, Savary, Harlan, Haltenhoff, Hirschberg, Natanson, Lyder Borthen, Lange und die anatomisch untersuchten Fälle von Alt, Schiess-Gemuseus, Treitel und Schäfer).

Nur selten ist bei traumatischer Aniridie die Linse in ihrer Lage erhalten aber kataraktös verändert (Beobachtungen von Fano, Mc Keown) und hierher ist auch unser Fall zu zählen, obgleich die Linse noch eine geringe Verschiebung nach oben zeigte, welche jedoch klinisch nicht erkembar war.

\section{Fall IV.}

Ueber denselben entnehme ich den klinischen Protokollen folgende Daten:

Am 10. September 1885 wurde der 56-jährige Fragner Johann Naber sub Prot. Nr. 12 auf die I. Augenklinik in Wien aufgenommen. Angeblich fiel er am Abend zuvor auf einen Stein, wobei er sich das rechte Auge verletzte. Bei der Aufnahme zeigte sich die Haut des Kinnes abgeschürft, in der Wangenhaut nahe dem unteren Orbitalrande rechterseits eine ca. $3 \mathrm{~cm}$ lange, oberflächliche Continuitätstrennung mit zackigen Rändern. Die Lidhaut an mehreren Stellen von Blutaustritten durchsetzt. Bindehaut des Bulbus intensiv geröthet, gewulstet. Ringförmige Ciliarinjection um die Hornbaut. Nach innen ca. $2-3 \mathrm{~mm}$ vom Limbus entfernt, ist die Sklera durchrissen

O Glesby zu dem merkwürdigen Schlusse, dass die Iris schon früher ringsum loggelöst war und jetzt dem leichten Zuge der Pincette folgte. Leider sagt or nicht, auf welche Weise sie bis zu dieser Zeit in der Kammer ausgespannt erhalten worden war. 
und zeigt eine ungefahr $3 \mathrm{~mm}$ lange, vertikal verlaufende, mit tiefschwarzen Pigmentmassen ausgefüllte, annähornd lineare Wunde. Hornhant glänzend, in der oberen Hälfte von senkrecht verlaufenden streifigen Trübungen durchsetzt, Vorderkammer vollständig mit dunkelrothem Blute erfüllt. Lichtempfindung scheint $\mathrm{zu}$ fehlen.

Das linke Auge, soviel äusserlich wahrnehmbar, normal.

Die Therapie bestand in Bettruhe und Anregung der Diaphorese durch Natrium salicylicum und Flores Tiliae.

Am 17. September war das Blut in der Vorderkammer bereits vollkommen resorbirt. Man sah nun, dass die Iris von ihrer unteren Insertion vollkommen losgerissen und in das obere Drittel der Kammer gerückt war. Die Pupille erschien als querverlaufender, ganz schmaler, schlitzförmiger Spalt.

Am 23. September 1885 verliess der Kranke auf sein Verlangen die Krankenanstalt. Es bestand noch intensive Ciliarinjection und Wulstung der Augapfelbindehaut. Der Skleralruptur entsprach eine pigmentirte Narbe. Im Ubrigen hatte sich der Status bezuglich Iris und Pupille nicht geändert. Aus dem Fundus war kein rothes Licht zu erhalten. T n. Amaurosis (?) Bulbus bei Betastung nicht schmerzhaft. Linkes Auge normal.

Am 12. Oktober 1885 liess sich Patient abermals anf die Klinik aufnehmen, da die Reizung des rechten Auges anhielt. Am 13. Oktober wurde in Nareose die Enucleation des Bulbus vorgenommen.

Der in Müller'scher Flüssigkeit conservirte und in Alcohol nachgehärtete Bulbus zeigt auf dem verticalen Durchschnitte folgende Verhältnisse: Die Dimensionen sind normal, die Vorderkammer tief, da die Iris bis in die Ebene des Ciliarkörpers zurückgesunken ist. Die Regenbogenhaut zeigt sich nur innen and aussen fixirt, so dass eine doppelte Iridodialyse oben und unten entsteht. Die unten gelegene ist jedoch bedeutend breiter. Die Iris ist sehr schmal, die Pupille spaltförmig, quergestellt, In der Vorderkammer kein Inhalt. Die Linse fehlt. Der Glaskörper, welcher grösstentheils von membranöser Structur ist, bildet nur im unteren Theile eine compactere und blutig imbibirte Masse, der obere Theil ist verflissigt und entleerte sich bei der Spaltung des Augapfels. Er ist nach vorne durch ein zartes, durchscheinendes Häutchen abgegrenzt, auf welchem die Iris aufliegt. Netz- and Aderhaut sowie der ganze hintere Bulbusabschnitt zeigen makroskopisch keine Abweichung von der Norm. 
Die beiden Bulbushälften wurden in Celloidin eingebettet und in Serien zerlegt, indem sie zuerst dem verticalen Meridian parallel geschnitten wurden, während die seitlichen Parthien frisch eingebettet und sectorenweise ebenfalls in Serien geschnitten wurden.

\section{Mikroskopische Untersuchung.}

Auf dem meridionalen verticalen Durchschnitte des vorderen Augapfelabschnittes (Fig. 8) erscheint die Hornhaut etwas dicker, ihr Gewebe lockerer, die interlamellären Spalten bedeutend verbreitert, besonders in den hinteren Hornhautschichten, ohne entzündliche Infiltration. Ihr Epithel vollständig erhalten, normal. Nur die Membrana Descemetii sammt den hinteren Hornhautlamellen ist besonders in den centralen Parthien der Cornea stark gewellt. Das Endothel vorhanden, nicht gewuchert. Am Limbus verdünnt sich die Hornhaut beträchtlich, da die Sklerotica nur etwas über die Hälfte der Hornhautdicke hat. An etlichen Stellen schiebt sich zwischen Epithel and Bowman'sche Membran eine ganz dünne Schicht von reichlich mit Rundzellen durchsetztem, Gefässe führendem Gewebe ein kurzes Stück weit vom Limbus aus yor.

Oben ist die Continuität des Skleragewebes in einer zackigen Linie unterbrochen, der Zwischenraum zwischen den beiden Rissenden vollständig ausgefüllt durch eine aus zarten, welligen Fasern bestehende, von jungen Kernen reichlich durchsetzte und mit Eosin nur blassroth gefärbte Bindegewebsmasse. Nur einige derbere, wie geknickt aussehende Faserbündel der mittleren Skleralschichten sind unzerrissen geblieben. Ausserdem sind auch die äussersten, schon etwas lockerer gefügten und den Übergang zum episkleralen Gewebe bildenden Faserzüge in ihrem Zusammenhange erhalten, jedoch leicht nach aussen vorgebaucht. Diese Unterbrechung der Sklera betrifft genau die Gegend des Schlemm'schen Canales, von welchem deshalb auch keine Spur vorhanden ist, und durchdringt die Sklera in schiefer Richtung ungefähr der Frontalebene entsprechend, so dass also die äusseren Schichten weiter hinten durchtrennt sind, als die inneren.

Das Ligamentum pectinatum ist ebenfalls in Mitleidenschaft gezogen. Sein Balkenwerk ist zusammengefallen, die einzelnen Bälkchen stark gefältelt. Seine ganze Länge ist reducirt, seine hintere Anheftung fehlt, da die Iris vollständig 
und genau an ihrem Ciliaransatze abgetrennt ist, ohne hier Uberreste zurückzulassen.

Der Ciliarkörper ist normal gebildet und frei von jedem entzündlichen Zeichen. Die Ciliarfortsätze hingegen sind deutlich und manche sogar beträchtlich nach vorne gezogen und sowie der vor dem Ciliarmuskel gelegene Theil des Ciliarkörpers innig mit dem oben beschriebenen Schaltgewebe in der Sklera verwachsen. Ihr Pigmentepithel hört am Rissrande, welcher an das Ligamentum pectinatum stösst, plötzlich auf. An einer Reihe von Schnitten lässt es deutliche Wucherungsvorgänge erkennen, so dass eine 5-6fache Lage von pigmentirten Epithelzellen vorliegt. Hier ist auch das bindewebige Stroma der Ciliarfortsätze mit dunkelbraun pigmentirten Rundzellen durchsetzt. Stellenweise springt von dem Schaltgewebe in der Sklera ein auf dem Durchschnitte dreieckiger, aus feinen Fasern bestehender Zipfel in den Kammerwinkel vor, welcher zum Theile mit den Ciliarfortsätzen in Verbindung tritt zum Theile in Gestalt feiner, den Zonulafasern gleichenden Fäden, sich frei in die Kammer erstreckt.

An der unteren Circumferenz des Limbus findet sich ebenfalls eine Zusammenhangstrennung der Sklera, welche nur die inneren Schichten betrifft, während die äusseren unversehrt uber den Riss himwegziehen. Die Tiefe desselben beträgt ungefähr die halbe Dicke der Sklera. Auch das Ligamentum pectinatum ist quer durchtrenut und zwischen die Rissenden desselben ein lockiges, zartes Bindegewebe eingelagert, das stellenweise zahlreiche Kerne enthält. Vom Schlemm'schen Canale ist anch an diesem Abschnitte nichts wahrzunehmen. Knapp hinter der Stelle, wo die Membrana Descemetii in das Balkenwerk des Ligamentum pectinatum übergeht, zeigt sich ein lockeres, aus zarten Bindegewebsfasern bestehendes Gebilde, welches mit einer dreieckigen Basis entspringt, indem Fasern von der Grenze der Descemet'schen Haut nach hinten und andere von dem Ursprunge des Ligamentum pectinatum nach innen und vorne ziehen und sich unter spitzen Winkeln treffen. Dieses Gebilde zieht dann, sich allmählich verschmächtigend, gegen die vordere Glaskörpergegend hin. An den Schnitten, welche einer etwas weiter nach innen und unten gelegenen Stelle entsprechen (Fig. 13), erreicht dieses Gebilde eine bedeutende Mächtigkeit. Hier ist die Sklera wieder in ganzer Dicke durchrissen und die beiden Wundränder durch eine mehr als $1 \mathrm{~mm}$ dicke Narbenmasse mit einander vereinigt, 
die sich in Gestalt eines zugespitzten Zapfens gegen die Bulbusachse in die Vorderkammer vorschiebt und an deren Hinterfläche das Corpus ciliare und die Processus ciliares angewachsen sind. Ihr Epithel zeigt hierbei energische Wucherung. -

Unten innen (Fig. 12) hingegen ist die Sklera intact, ebenso der Schlemm'sche Canal. Die Ciliarfortsätze sind ähnlich wie im I. Fall ohne Einschaltung eines $Z$ wischengewebes gegen das eingerissene Ligamentum pectinatum hingezogen. Der Cireulus arteriosus iridis major ist erhalten.

Der Glaskörper besteht aus einem sehr zarten, feinstreifigen Gewebe, welches fleckweise von rothen Blutkörperchen, die noch sehr gut erhalten sind, durchsetzt ist, stellenweise auch Wanderzellen eingelagert entbält; er grenzt sich nach vorne mit einer Glasmembran $a b$, welche keine Andeutung einer tellerförmigen Grube trägt. Von der Linse oder Linsenkapsel ist nichts auffindbar. Auch an dieser Seite (unten) ist von der Iris auch nicht der mindeste Rest an ihrer Ansatzstelle zuruickgeblieben. Die Ciliarfortsätze, welche Hyalindegeneration zeigen, siud auch hier etwas nach vorne gezogen und mit dem Ligamentum pectinatum direct verwachsen. Die Rissstelle am Ciliarkörper ist durch Zusammenziehung des Gewebes ausserordentlich schmal geworden und durch Einrollung des Pigmentepithels der Ciliarfortsätze zum grössten Theile gedeckt. Der noch übrige Theil der Rissstelle tritt in directe Verbindung mit der Basis des Ligamentum pectinatum, welches so wie das von ihm abzweigende neugebildete Gewebe reichlich mit pigmentführenden Rundzellen durchsetzt ist. Dieses neugebildete Gewebe überlagert auch, von massenhaften Blutaustritten durchsetzt, den Ciliarkörper, ist mit den Fasern der Zonula Zinnii aufs innigste verwebt and lässt sich nach rïckwärts bis zur Ora serrata verfolgen, wo die Blutungen allmäblich an Mächtigkeit zunehmen. Hier und da finden sich auch noch weiter hinten im Glaskörper Zellhaufen, welche uveales Pigment führen. -

Die Iris, welche, wie schon erwähnt, von ihrem Ciliaransatze losgetrennt ist, liegt ungefähr in der gleichen Ebene, in welcher man sie in aphakischen Augen vorzufinden pflegt. Knapp hinter ihr spannt sich ein Diaphragma aus, welches die vordere Begrenzung des Glaskörperraumes bildet und aus der Glasmembran des Corpus vitreum gebildet und durch das aus dem Kammerwinkel entspringende, schon oben beschriebene feinfaserige Gewebe verstärkt wird. Mit demselben steht der Rissrand der Iris besonders im Bereiche der oberen Dia- 
lyse durch feinfaseriges Gewebe, welches nur spärliche Kerne und Pigmentkörnchen eingelagert enthält, in Verbindung. Die Iris, welche keine Verdünnung, wohl aber eine ziemlich beträchtliche Verschmälerung ihrer Spreite aufweist, verjüngt sich gegen den Rissrand. Da, wo derselbe an das Glaskörperdiaphragma angeheftet ist, ist das Irisgewebe etwas auseinandergezerrt, die hinteren Bindegewebslagen nach rückwärts eingerollt. An den Stellen, wo der Rissrand frei liegt (also besonders unten), ist er abgerundet, indem die vorderen Lagen nach hinten und die rückwärtigen nach vorne eingebogen sind. Das Pigmentepithel erreicht nicht vollständig den freien Rand, sondern endet schon etwas früher noch an der Hinterfläche der Iris. Das Irisgewebe zeigt keine weiteren Veränderungen als eine auffallende hyaline Degeneration der Gefässwandungen, ohne sonstige Zeichen von Atrophie oder Sklerose. Auch der Sphincter iridis ist nicht verändert.

Bei Durchmusterung der Serien zeigt sich, dass die $\mathrm{Pu}$ pille, welche in vertikaler Richtung sebr schmal, in horizontaler dagegen sehr breit, also spaltförmig ist, nach innen verzogen ist. Daher erhält man aussen noch ganz nahe beim verticalen Meridian Schnitte, an welchen die Pupille nicht mehr getroffen ist. Dieser undurchbrochene Antheil der Iris liegt ganz in der oberen Hälfte der Kammer und rückt, je weiter man nach aussen kommt, unter gleichzeitiger geringer Verschmälerung immer höher hinauf und näher in den Kammerfalz, bis er endlich im äusseren oberen Quadranten an den Kammerwinkel anstösst und mit dem Ciliarkörper verwachsen ist.

Dieser Uebergang der Dialyse in die normale Irisinsertion findet in folgender Weise statt:

Die sich nach der Seite ihres Rissrandes verschmächtigende und nach und nach zuschärfende Iris tritt, sobald sie wegen der allmählichen Verschmälerung der Iridodialyse bis an die Spitzen der Ciliarfortsätze herangerückt ist, durch einen aus spindeligen, langen Zellen mit länglichen Kernen bestehenden Faden in Verbindung mit der Basis des Ligamentum pectinatum, wobei es den Anschein hat, als ob diese fasrigen Zellen directe Abzweigungen und Verlängerungen seines Balkenwerkes wären (Fig. 11). An dem rugespitzten Theile der Iris ist kein Pigmentblatt vorhanden, da es mit einem verdickten, offenbar in Wucherung begriffenen Rande schon früher an der Hinterfläche der Regenbogenhaut endet. Die Gefässe dieser Gegend sind sämmtlich blutleer, ihre Wan- 
dungen verdickt, hyalin, ihr Lumen entweder vollständig aufgehoben oder bis auf einen feinen Spalt verengt.

In dem Maasse als die Iris weiter in den Kammerwinkel rückt, wird der erwähnte Faden natürlich kürzer und gleichzeitig dicker, indem sich mehrfache zarte Bindegewebslagen darauf schichten, welche ganz das Aussehen des (etwas gezerrten) Irisstromas besitzen und auch etliche Gefässchen enthalten. Auch hier fehlt noch das Pigmentepithel. Dieses ist der letzte Bestandtheil der Iris, welcher wieder auftritt, Es sei noch bemerkt, dass auch in dieser Gegend (also im oberen äusseren Quadranten) die Sklera nicht intact ist, sondern ungefähr die zwei inneren Drittel ihrer Dicke eingerissen und durch junges Narbengewebe verlöthet sind. Dies ist die einzige Stelle, an welcher die Iris, wenn auch nur in kurzer Strecke ihre normale Insertion behalten hat, während sie sonst ringsum von ihrem Ciliaransatz abgetrennt ist.

Auf Schnitten, welche durch den innereu Theil der Corneoskleralgrenze (Fig. 9) geführt sind, also durch die Stelle, wo in vivo die Skleralruptur und der Prolaps der Uvea sichtbar war, ist die Bindehaut stärker vorgewölbt, heerdweise von Rundzellen und Blutaustritten durchsetzt. Das subconjunctivale Gewebe ist etwas verdichtet und durch eine Lage neugebildeten Bindegewebes verstärkt. Hier zeigen sich wieder die schon oben ausführlich beschriebenen pigmentführenden Zellen (Pigment in den Lymphzellen der perivasculären Rüume, in den Wanderzellen, in den fixen Bindegewebszellen der Conjunctiva und Subconjunctiva) in grosser Menge. Die Sklera ist genau an der Stelle des Schlemm'schen Canales vollständig durchtrennt, ihre Rissränder sind auseinander gewichen und zwischen ihnen hervor quillt die Iris, welche aber nicht wie bei einem gewöhnlichen Irisprolaps beutelförmig vorgestülpt und mit ihrer Vorderfläche nach aussen gekehrt ist, sondern sie ist auch hier von ihrem Ansatze abgelöst, nach vorne umgeschlagen und in diesem gefalteten Zustande vorgefallen. Es bildet demnach das Pigmentblatt, welches streckenweise abgestreift, stellenweise in Wucherung begriffen ist, die äussere Ueberkleidung des Vorfalles. Die Iris ist hier nur um Weniges zellreicher als sonst, ihre Gefässe hingegen sehr dicht an einander gedrängt, ihre Wandungen hyalin, verdickt. An der Durchtrittstelle durch die Sklerawunde ist die Regenbogenhaut zusammengedrückt, verdünnt, mit ibrer Vorderfläche direct an die skleralen Faserbündel angewachsen; zwischen ihrer 
Hinterfläche und dem skleralen Rissrande hingegen ist suculentes kernreiches Bindegewebe eingeschaltet in einer Mächtigkeit, welche der Dicke der Iris ungefähr gleichkommt. Dasselbe tritt in unmittelbare Verbindung einerseits mit dem neugebildeten Gewebe in der Episklera, welches den Prolaps überzieht, andererseits mit dem schon mehrfach erwähnten, hinter der Iris liegenden Diaphragma. Hierbei vermittelt es auch zngleich die Verschliessung der Risswunde am vorderen Ende des Ciliarkörpers. Stellenweise ist der Ciliarmuskel von seiner Insertion an der Sklera abgelöst. Von seinen Gefässen treten zarte Sprossen in das junge Narbengewebe ein. Die Ciliarfortsätze and der Ciliarkörper zeigen hier nur die schon früher erwähnten Veränderungen.

Der Uebergang vom Irisvorfall zur oberen DiaJyse findet in der Weise statt, dass der gedoppelte Antheil der prolabierten Iris immer kleiner wird, indem er sich aufrollt, bis endlich nur die einfache, ungefaltete Iris durch den skleralriss hindurchgesteckt erscheint (Fig. 10). Dieser Theil wird nach and nach kürzer, so dass er nicht mehr über die äussere Oberfäche der Lederhaut vorragt und von dem jungen Bindegewebe, welches hinter ihm aus der Ruptur herauszieht und glatt uber ihn hinwegstreicht, überdeckt wird. Weiterhin zieht sich die Iris immer mehr zuruck; sie ist erst noch mit einem kleinen Endchen eingeklemmt, schliesslich liegt sie ganz innerhalb der Bulbuskapsel, während ihr Platz in der Skleralruptur vom jungen Narbengewebe ganz ausgefüllt wird. Mit diesem steht der Irisrand anfangs noch vermittelst feiner Fasern in Zusammenhang, doch lös sich derselbe bald.

Der Uebergang vom Irisvorfall zur untereu Dialyse ist ganz analog, nur ist nach dieser Seite der vorgestülpte Irisantheil bedeutond breiter als der in der Skleraloffinung steckende, halsartig eingeschnürte, so dass auf Schnitten, welche schon die ausgebildete Dialyse und die solide Skleralnarbe treffen, noch zusammengebalite Reste der Iris ausserhalb der Bulbuskapsel unter der Bindehaut liegen (vgl. Fig. 13).

Der hintere Bulbusabsehnitt bietet wenig Bemerkenswerthes. Der Glaskörper ist in der schon erwähnten Weise verändert, theils flüssig, theils fibrillär geronmen, von Blutaustritten durchsetzt, welche nach unten an Mächtigkeit bedeutend zunehmen. Die Retina und Chorioidea sind gut erhalten, der Sklera anliegend. Der Sehnervenkopf ist besonders in der Gegend der Lamina cribrosa zellig infiltrirt aber nicht geschwollen, seine 
Gefässe sind strotzend gefüllt. Auch die peripheren Antheile des Sehnerven sind zellreicher; dagegen zeigen die Ciliarnerven keine entzündlichen Erscheinungen und färben sich sowie der Sehnervenstamm nach Weigort.

Eine kurze Zusammenfassung der mikroskopischen Befunde an diesem Auge ergiebt, dass die Sklera infolge des Traumas, dessen Natu leider nicht genauer festzustellen war, an der imneren Circumferenz nahe dem Hornhantrande geborsten war und das Ligamentum pectinatum und der Schlemm'sche Canal hierhei durchrissen wurden.

Die Skleralruptur ist nur ein verhältnissmässig kurzes Stück penetrirend, ungreift aber, mit Ausuabme einer kurzen Strecke im äusseren unteren Quadranten, als incompleter Riss den ganzen Hornhautumfang. Hier sind allenthalben die inneren Faserschichten der Sklerotica durchtrennt, während die äusseren intact blieben, ein Verhalten, welches den Befund, welchen Schäfer an einem mit Iridodialysis behafteten Ange machte, bestätigt. Derselhe fand nämlich eine incomplete Ruptur der Sklera nahe der Hornhautgrenze, welche nur die beiden inneren Drittel der Lederhant betraf. Doch sind stellenweise (vergl. Fig. 11) auch einzelne Faserbündel aus den mittleren Skleralschichten erhalten geblieben, während die nach innen und nach aussen davon gelegenen zerrissen. Dies deutet offenbar auf eine sehr verschiedesie Dehnbarkeit der einzeluen Lederhautfaserbïndel und berechtigt im Allgemeinen zu dem Schlusse, welchem Schiess-Gemuseus gelegentlich der Untersuchung eines mit Irideremie behafteten, leicht atrophischen Bulbus, an welchem die inneren Skleralschichten sehr stark gefaltet waren, während die oberflächlichen glatt darüber hinwegzogen, Worte giebt: dass uämlich die Elasticität der äusseren Skleroticallamellen eine bedeutendere sei als die der immeren. Auch Schäfer folgert aus seinem Falle das Gleiche. Fs ist von Wichtigkeit, dass an keiner Stelle die beiden Wundränder der Skleralruptur 
Beiträge zur patholog. Anatomie d. traumatischen Aniridie etc. 39

sich eng aneinander legten und so direkt ohne Betheiligung eines Zwischengewebes verwuchsen, sondern dass ïberall eine mehr minder breite Schichte von jungem, noch kernreichem Bindegewebe eingeschoben ist und den Verschluss vermittelte.

Während klinisch nur eine breite Iridodialyse im unteren Bulbusabschnitte wahrgenommen werden komnte. zeigte sich in dem vertical durchschnittenen Bulbus noch eine zweite, schmälere, nach oben gelegene. Die mikroskopische Untersuchung ergab nun den interessanten Befund, dass beide Dialysen doch nur Abschnitte einer einzigen, sehr ausgedehnten, fast circulären Abtreunung der Regenbogenhaut von ihrer ciljaren Insertion sind, da auch innen, wo der Prolaps sich befindet eine Losreissung der Tris zu constatiren ist. Jedenfalls ist dieselbe früher erfolgt als der Irisvorfall, da sich sonst die Iris offenbar in derselben Weise hätte vorstülpen müssen wie in dem erstbeschriebenen Falle und wie man es überhaupt bei Irisprolaps zu finden gewohnt ist, nämlich dass die vorderen Irisschichten nach aussen gekehrt sind, nicht aber wie hier das Pigmentepithel. Dass es iiberhaupt zu einem Irisprolaps kam und sich die dialysirte Regenbogenhant nicht nach der Seite der angeheftet gebliebenen Parthie zurückzog, führe ich darauf zurück, dass das vorstürzende Kammerwasser den nun schlaffen Irisring mit sich riss, hauptsächlich aber darauf, dass die Linse aus ihrer Verbindung gelöst, durch die Skleralruptur ausgetrieben wurde und dabei die Tris mitzog.

Da von der Linse gar keine Reste auffindhar sind, muss angenommen werden, dass sie durch einen Schlit $z$ in der Bindehaut austrat.

Auffallend ist, dass die Regenbogenhaut, welche ja nur an einer ganz kurzen Strecke ihres Umfanges noch angewachsen war und dadurch mit den ernährenden Gefässen in Verbindung stand, nach einem mehr als einen 
Monat währenden Bestande der Dialyse keine auffalligen Ernährungsstörungen zeigt. Denn die hyaline Degeneration der Gefässwandungen ist wahrscheinlich nicht auf solche zurïckzuführen, sondern als gewöhnliche senile Veränderung zu betrachten. Finden wir ja doch bei dem 56 jährigen Manne auch in den Hälsen der Ciliarfortsätze schon betrüchtliche Hyalindegeneration, wie sie zuerst von Rosa Kerschbaumer, dann von Fuchs als senile Veränderung beschrieben wurde. Dass an der Stelle, wo die Dialyse in die normale Insertion ibbergeht. ein Theil der Gefässe in Ciliartheile der Iris obliterirt oder verengt ist, darf mus nicht Wunder nehmen, da gerade diese Stelle einer grösseren Zerrung ausgesetzt ist, welche sich auch durch eine Verdiinnung der Irisdicke kundgiebt. Im Gegentheil ist es auffallend, dass die Conmunication durch den Circulus arteriosus iridis minor und die anderen Anastomosen im Irisgewebe hinreichten, die ganze Iris genügend mit Blut zu versorgen und vor Atrophie zu bewahren.

Was den Verschluss der Risswunde an der Iris anbelangt, so findet er in zweierlei Weise statt. Ersteus ohne Hinzutreten irgend welchen neugebildeten Gewebes, einfach dadurch, dass die mittleren Trisschichten sich zuruickziehen und die vorderen und hinteren sich gegen einander neigen und mit Endothel ibberkleiden; zweitens dadurch, dass der Rissrand in Verbindung tritt mit einem aus zartem Bindegewebe bestehenden Hüutchen an der vorderen Glaskörperbegrenzung. Dabei zeigt der Rand ein dem früher beschriebenen gerade entgegengesetztes Verhalten, indem die vorderen und hinteren Schichten durch den Zug der neugebildeten Meribran anseinandergezogen und die Narbe dadurch bedeutend verbreitert ist. Schäfer beobachtete in seinen Fällen eine etwas andere Art des Wundverschlusses: „Der Wundrand des abgerissenen Irisstückes ist von einem zarten, spindelzelligen Exsudatbelag überzogen, über welchen das vordere Irisendothel his rur Pigmentschicht hinüber- 
gewuchert ist." Im zweiten Falle von Iridodialyse ,ist das abgetrennte Stück an seiner Wundfläche von vorne nach hinten zugeschärft, der Wundrand selbst erscheint ganz glatt, ohne irgendwelche Unebenheit, ron einer feinen organisirten, vorwiegend aus laugen Spindelzellen bestehenden Exsudatschicht bedeckt, über welche das Endothel der vorderen Irisfläche bis zur hinteren Begrenzungsschicht hinzieht."

Wie in den drei erst beschriebenen Fällen ist auch hier die Iris vom Corpus ciliare abgerissen ohne einen noch so kưzen Stumpf zurückzulassen. Die Wunde im Ciliarkörper schloss sich, wie aus den Abbildungen ersichtlich, theils dadurch, dass durch Heranziehung der Ciliarfortsätze gegen das in die Skleralruptur eingeschaltete Narbengewebe eine innige Verlöthung eintrat, theils dadurch, dass die Ciliarfortsätze weit nach vorne bis iiber das vordere Ende der Lamina Descemetii gezerrt und durch eine mehr oder minder mächtige Lage von neugebildetem Bindegewebe hier fixirt wurden. Endlich ist an manchen Stellen das Narbengewebe aus der Sklera so weit in die Vorderkammer gewuchert, dass die ursprünglich vorhandene Wundhöhle im vorderen Theile des Corpus ciliare dadurch ganz ausgefüllt ist und die Ciliarfortsätze an die HinterHäche der zapfenartig vortretenden Bindegewebsmasse angewachsen sind. Diese Verhältnisse scheinen mir von Wichtigkeit zu sein fuir die Entscheidung der Frage, wann die Ciliarfortsätze der klinischen Beobachtung zugänglich sein werden und wann nicht. Denn wenn der vordere Theil des Ciliarkörpers zusammengefallen ist und die Basen der Ciliarfortsätze gegen eine Skleralnarbe oder an das Ligamentum pectinatum hingezogen sind oder wenn luxurirendes Narbengewebe sich vor ihnen entwickelt und in die Kammerbucht vorragt, so wird der ganze Ciliarkörper so verschmälert, dass er selbst bei sehr schiefem Einblicke ins Auge nicht sichthar wird oder er wird durch die Ge- 
websneubildung direkt verdeckt. Von Belang scheint mir dabei auch noch die Entwicklung des Ciliarmuskels zu sein, da in hypermetropischen Augen bei stark ausgebildeten circulären Fasern, welche ja gerade am vorspringendsten Theile des Ciliarkörpers liegen, die Bedingungen für das Sichtbarsein seiner Fortsätze von vorn herein bedeutend güustiger sind als in einem myopischen Auge mit ganz Hachem Corpus ciliare.

Die Atrophie der Ciliarfortsätze, welche von manchen Autoren in Anspruch genommen wird, dürfte überhaupt gar nicht in Betracht kommen, besonders da in manchen Fällen schon einige Tage oder Wochen nach der Verletzung, sobald das Blut resorbirt und die Medien wieder klar geworden sind, die Ciliarfortsätze nicht wahrnehmbar sind, wïhrend sie in anderen noch nach Jahren in gleicher Deutlichkeit sichtbar bleiben.

Auch eine Abreissung der Ciliarfortsätze, welche Samelson hypothetisch in Anspruch nahm, möchte ich nicht gelten lassen. Denn es scheint mir gar nicht möglich, dass durch ein stumpfes Trauma, welches zur Ablösung der Iris von ihrer Insertion führt, auch Ciliarfortsätze, welche nit der Regenbogenhaut ja nur in indirektem Zusammenhange vermittelst des Corpus ciliare stehen, abgetremnt werden sollen. Es wäre ja da viel eher denkbar, dass bei traumatischer Luxation der Linse, welche durch die Zonula direkt an die Processus ciliares angeheftet ist, bei etwas grösserer Festigkeit der ersteren und bei sehr nugestümer Finwirkung der Gewalt, eine Abreissung von Ciliarfortsätzen erfolgen könnte und doch ist ein solches Vorkommniss meines Wissens noch niemals beobachtet worden.

Schäfer fand bei der anatomischen Untersuchung eines vor 16 Tagen durch einen Schrotschuss verletzten Auges eine Hornhautnarbe, welche nahe ihrem Rande schräg von vorne nach binten gegen das Corpus ciliare gerichtet 
war, und dementsprechend eine ganz kurze Durchtrennung der Iris. Diese ,ist dicht an ihrem Aufsatze ans Lig. pect. abgerissen und hat oftenbar 4-5 Processus ciliares, welche in den Prüparaten fast unmittelhar ihr anliegen, beim $A b$ reissen mitgenommen." Hinter dem Ciliarkörper befand sich eine knäuelartig aussehende Narbe in der Chorioidea, Retina und Glaskörper, offenbar der Gegend entsprechend, wo das Schrotkorn aufgefunden wurde.

Dieser Fall beweist nun meiner Ansicht nach durchaus nicht, dass durch eine Iridodialyse Ciliarfortsätze abgerissen werden können. Denn da handelte es sich ja um einen Schrotschuss, wobei das Projectil durch die Hornhaut hindurchging und die Iris nahe ihrem Ciliaransatze sant den hinter ihr liegenden Ciliarfortsätzen durchschlug. Wenu man nun eine derart entstandene Durchtrennumg der Tris auch als Dialyse gelten lassen will, so kann doch keineswegs zugegeben werden, dass die Ciliarfortsiitze von der sich vou ihrem Ansatze ablösenden Iris mitgenommen wurden.

$D_{i}$ in meinem letztbeschriebenen Falle makroskopisch eine doppelte Iridodialyse vorgefunden wurde, welche sich jedoch bei histologischer Prüfung als eine einzige, durch einen Trisprolaps gewissermassen in zwei getheilte Dialyse zu erkennen gab, taucht die Vermuthung auf, dass wohl Manche von den Fällen, wo eine doppelte Dialyse klinisch diagnosticirt worden war, auf ahnliche Weise zu erklären sein dürften. Es kam ja dabei der Trisprolaps so klein bleiben, dass er von der Conjunctiva ganz verdeckt wird, insbesondere wenn nicht eine auffallige Pigmentirung in der Nähe des Limbus aufmerksam macht, nach dieser Richtung genauer zu untersuchen.

Ein glïcklicher Zufall fügte es, dass mir bald zwei hierhergehörige Fälle zux Beobachtung kamen, welche dazu angethan sind, die von mir gehegte Vermuthung zu bestätigen. Es mögen deshalb die beiden Krankengeschichten hier einen Platz finden: 


\section{Fall V.}

Ruptura selerae, Iridodialysis, Luxatio lentis sub conjunctivam o. d.

Georg Renerer, 60 Jahre alt, Tagelöhner, suchte am 23. Februar 1893 die I. Augenklinik auf, weil er seit einer Verletzung, die er vor einigen Wochen erlitten, schlecht sähe. Er hatte damals (eine genaue Zeitangabe war aus dem indolenten Patienten nicht herauszubringen) bei der Arbeit einen Streifhieb mit cinem Dreschflegel an die rechte Kopfseite erhalten. Die Augengegend soll damals verschwollen gewesen sein. Er blutete aus einer Wunde am Augenbrauenbogen.

Bei der Aufnahme in die Klinik war dieselbe schon verheilt, kaum sichtbar. Im Uebrigen zeigte das rechte Auge folgende Verhältnisse (vgl. Fig. 14): Lidhaut sehr schlaff, über den äusseren Winkel spannt sich eine verticale dünne Hautfalte, wodurch der äussere Theil des Oberlides eingerollt wird, so dass die Cilien am Bulbus schleifen. Das untere Lid zeigt eine stärkere Vorwölbung, seine Bindehaut etwas verdickt, das Epithel getrübt. Direct nach unten von der Cornea befindet sich eine kreisrunde, gelblich durchscheinende, elastische Geschwulst, genau von der Grösse der Hornhaut, welche auf 7 bis $8 \mathrm{~mm}$ vorragt und mit etwas eingezogener Basis leicht gehalst aufsitzt. Sie wird von einem sehr zarten Netzwerk von Bindebautgefässen übersponnen und ist sammt der Conjunctiva nach allen Richtungen in geringem Grade verschiebbar. Nach aussen schliesst sich an ihre Basis ein schiefergran pigmentirter, länglicher, mit dem Hornhautrande in einer Entfernung von $2 \mathrm{~mm}$ parallel laufender Streifen, von welchem sich, noch immer parallel mit dem Limbus, eine zarte Narbe nach anssen oben bis über den horizontalen Meridian fortsetzt. Eine ähnliche findet sich unten und imen bis in die Pingueculagegend hinaufreichend. Hornhaut vollständig normal ohne Aenderung ilurer Transparenz oder Wölbung. Die Vorderkammer oben von gewöhnlicher Tiefe, scheint nach abwärts etwas seichter zu werden, ohne fremde Inhaltsmassen. Die Iris ist vollständig von ihrem ciliaren Ansatze losgelöst and wird nur innen oben durch einen ungefähr $1 \mathrm{~mm}$ breiten Zipfel festgehalten, ausserdem spannen sich jedoch noch spinnenwebenartig zarte Fasern im oberen Umfange des Kammerfalzes annähernd radiär aus und fixiren den oberen Rand der Iris, welcher $2-3 \mathrm{~mm}$ von seiner Ansatzstelle absteht. 
Unten ist die Iris in ungefähr $9 \mathrm{~mm}$ Breite ebenfalls in der Gegend der Kammerbucht fixirt, doch entspricht ihre Lage einer weiter nach vorne gegen die Hornhant zu liegenden Stelle der Sklera. Durch diese doppelte Fixation der Iris entsteht nach aussen zu eine $7 \mathrm{~mm}$ breite, neue Pupille, welche aussen vom Corneoskleralrande, innen von dem nach aussen zu concaven Ciliarrande der abgetrennten Iris begrenzt wird; und nach innen eine zweite schmale, spaltförmige Pupille. Die Iris selbst ist ausserordentlich atrophisch, sehr dünn, die Pupille als ein schief von oben nach aussen unten ziehender, dunkler Strich markirt, welcher von einer weissen, etwas prominirenden Linie begleitet wird. Der obere Rand der Pupille liegt beiläufig im horizontalen Meridian, der untere knapp am Hornhautrande. Von der weissen Linie strahlen senkrecht graue, zarteste Fäserchen ans, wodurch die Iris das Aussehen einer feinen Vogelfeder erhält. Zwischen den Fasern erscheinen einzelne, sehr stark atrophische Stellen von dunkelgraublauer Farbe. In der innen gelegenen Dialyse zieht vertical von oben nach unten ein undurchsichtiger weisser Streifen, der an seiner breitesten Stelle oben mit dem Irisrande in Verbindung steht, während sein unteres Ende ein wenig nach rückwärts gewendet ist. In der ganzen Ausdehnung dieser Spalte sind die Ciliarfortsätze ausserordentlich deutlich als dunkelbraune Zapfen und Wärzchen mit gelblichen Kuppen sichtbar. Im äusseren Umfange des Kammerwinkels ist keine Spur von ihnen zu entdecken. Die Linse feblt an ihrer normalen Stelle. Im durchfallenden Lichte leuchten beide neuen Pupillen hellroth auf. Im Glaskörper zahlreiche frei schwimmende Flocken und Punkte und eine aussen unten fixirte, geisselartig schwingende, strangförmige Trübung. Der Fundus normal.

Am linken Auge ausser Blepharophimosis und centralen Hornhautflecken nichts Pathologisches.

S. R.F.z $-2^{\prime}$; mit $+3 \frac{1}{2}$ F.z $-15^{\prime}$ mit $+2 \frac{1}{2}$ Schw. $1,4-8^{\prime \prime}$

S. L. ${ }^{20 / 200}$ obne Besserung durch Gläser S; $\mathrm{S} 1,0-8^{\prime \prime} \mathrm{mit}+1 / 7$ Schw. 0,7-7".

Am 2. Mărz extrahirte ich die unter die Conjunctiva luxirte Linse. Canthoplastik.

10. III.: Patient verlässt die Anstalt mit geheilter Bindehautwunde. Lidspalte verlängert. Trichiasis behoben. Uebriger Befund unverändert. 


\section{Fall VI.}

Iridodialysis o. d. Cicatrix corneae cum synechia anteriore o. $d$.

Am 14. Mai 1893 besuchte Josef Fürst, Hausbesorger, 57 Jahre alt, die Ambulanz der I. Augenklinik, da ihm vor einigen Tagen Kalkstaub in beide Augen geflogen war.

Dabei konnte ich folgenden Befund am rechten Auge erheben (vgl. Fig. 15):

Lider normal, nur ein wenig zurückgesunken. Lidbindehaut leicht injicirt, seröses Secret liefernd, welches die Cilien verklebt. Bulbus etwas verkleinert, blass. Cornea ebenfalls ein wenig kleiner und flacher als links. An ihrer oberen $\mathrm{Pe}-$ ripherie befindet sich eine direct in die Sklera übergehende, völlig undurchsichtige, milchweisse Narbe, welche ungefähr $4 \mathrm{~mm}$ Breite besitzt. Deren untere mittlere Parthieen werden eingenommen von einer ca. $5 \mathrm{~mm}$ langen, $2 \mathrm{~mm}$ breiten Masse, die in ihrer äusseren Hälfte braunroth, sammtartig ist und wie Irisgewebe aussieht, während der innere Theil blaugrau bis blauschwarz gefärbt ist und eine hirsekorngrosse, schwärzliche, mehr prominente Stelle besitzt. Während im Uebrigen die Grenze der Narbe gegen das durchsichtige Hornhautparenchym ziemlich scharf ist, erscheint sie im innersten Antheile stark verwaschen. Die Vorderkammer ist etwas seichter, die Iris in ihrer ganzen oberen und inneren Peripherie also in halbem Umfange von dem ciliaren Ansatze abgelöst. Ihre innere Grenze zieht fast vertical von der Mitte des inneren unteren Quadranten des Limbus zum Innenrande der blauschwarzen Masse in der Hornhaut, ihre obere Grenze fast horizontal von der Mitte des äusseren oberen Hornhautumfanges zum Aussenrande dieser Masse. Die Pupille ist klein, dreieckig, zur Hornhautnarbe hingezogen, ihre obere Hälfte dadurch verdeckt. Die Iris ist stark atrophisch, ihre Fasern straff gespannt. In ihrem Gewebe mehrere braune Pigmentflecken eingelagert. Im äusseren Theile der Iridodialyse sind mehrere feine graue Fäden sichtbar, welche atrophirten Irisfasern gleich sehen. Am inneren Rande der Iris ist die oberste Parthie sehnigweiss. Bei gehobener Blickebene sieht man in der Pupille ein wenig hinter ihrer Ebene eine weisslichgraue Masse, welche ihre Fortsetzung im inneren Theile der Dialyse findet, wo sie eine nach unten convexe Grenze und gelblichweisse Farbe zeigt. Ciliarfortsätze sind auf keine Weise sichtbar. 
Beiträge zur patholog. Anatomie d. traumatischen Aniridie etc. 47

Im durchfallenden Lichte erscheint Pupille und Dialyse dunkel, nur bei einer einzigen Blickstellung (leicht nach links gewendetem und gehobenem Blick) erhält man einen gelblichweissen schillernden Reflex im inneren Theile der Dialyse. $\mathrm{V}=\mathrm{F}$. z. - $\mathrm{I}^{\prime}$ unsicher, L. A. bis auf Conjunctivalcatarrh normal.

Die Verletzung hatte im Jahre 1878 (März), also vor 15 Jahren, stattgefunden, indem dem Patienten in der Nacht um 2 Uhr beim Wagenwaschen das hintere Ende des zum Wagenheben dienenden Hebels in die rechte Augengegend schnellte. Er wurde bewusstlos und blieb so drei Stunden liegen, bis man ihn fand, ihn zum Bewusstsein brachte und ihm eine Wunde an der rechten Stimbälfte mit einem nassen Tuche verband. Sodann wusch er den Wagen weiter. Am nächsten Tage kam er auf die Klinik Arlt, wo eine Sprengung des Augapfels diagnosticirt wurde. $V=0$. Erst gegen Ende der 9 Monate währenden ambulatorischen Behandlung soll er wieder Licht und Dunkel unterscheiden gelernt haben. Das Auge war seitdem sehr reizbar, brannte und thränte bald. -

In beiden Fällen wax also klinisch eine doppelte Iridodialyse zu erkennen; doch zeigte sich die Grenze beider Dialysen durch einen Irisvorfall gebildet, der im 1. Falle durch die Skleraluptux nach unten, im 2. Falle durch die Cornealwunde nach oben stattgefunden hatte. Nach der histologischen Untersuchung des Falles IV. lässt sich wohl mit Sicherheit annehmen, dass beide Male an dieser Stello die Iris ebeufalls dialysirt und dann erst prolabirt war.

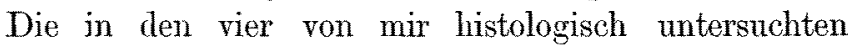
Fällen von Iridermie resp. Tridodialyse gefundenen Veränderungen im Kammerwinkel stehen im vollsten Einklange mit den von Treitel beschriebenen. In dessen Falle handelte es sich um Aniridia totalis et Aphakia traumatica bei einem 60jährigen Manne in Folge eines Stockschlages. Die Enucleation des Bulbus war 2\% Monate nach der Verletzung wegen sympathischer Reizung des anderen Auges vorgenommen worden.

Es fand sich in der Sklera dicht neben dem Rande der Cornea eine aus kernarmem, faserigem Gewebe bestehende 
Narbe, welche ,in grosser Ausdehnung durch den Schlem m'schen Canal geht, der vollkommen verschlossen ist, während er an den anderen Schnitten sehr deutlich hervortritt; sie ist ca. $12-15 \mathrm{~mm}$ lang und verläuft fast concentrisch mit dem Corneoskleralrand in einem Abstande von ca. 1 bis $11 / 2 \mathrm{~mm}$.

Die Ciliarfortsätze ziehen schräg nach vorn und medialwärts und sind zum Theil an der Sklera neben der Narbe, zum Theil an dieser selbst angelöthet." "Von der Tris nirgends eine Andeutung zu finden; man bekam den Eindruck, als ob aus einem sonst ganz normalen Auge die Iris auf das Sorgsamste, ohne Zurücklassung irgend welcher Reste und ohne Beschädigung der angrenzenden Parthien, entfernt wäre." Eine Abbildung illustrirt diese Verhältnisse, welche denen in meinem vierten Falle streckenweise vorgefundenen vollkommen entsprechen.

In gewissem Gegensatze dazu stehen die Befunde in zweien von den drei Schäfer'schen Fällen.

In dem Falle I. (Irideremia et Aphakia traumatica o. s. nach Ruptura bulbi), bei welcher die Enucleation 8 Monate nach der Verletzung stattgefunden hatte, war „,von der Iris auf beiden Seiten kaum noch eine Spur nachweisbar. Sie ist, wie deutlich zu ersehen, an ihrem Ansatze ans Corpus ciliare abgetrennt. ... Es findet sich noch ein ganz minimaler Irisstumpf vor, welcher fast die Form eines kurzen vorn abgerundeten Beer'schen Messers zeigt und etwas mit Rundzellen infiltrirt erscheint. Man bemerkt ganz deutlich, wie die Pigmentschicht der Iris die Ueberkleidung des Wundrandes uibernommen hat, über die $\mathrm{Ab}$ rissstelle hinibergewuchert ist und auf einem feinfaserigen, vorwiegend aus schmalen Spindelzellen bestehenden Narbengewebe aufliegend, sich bis zur vorderen Endothellage hin erstreckt, welche letztere sich in der Vernarbung des Wundrandes nicht activ betheiligt zu haben scheint."

In Schäfer's Fall III. (Iridodialysis traumatica o. s., 
Luxatio lentis, Ruptura sclerae incompleta. - Enucleation $3 \frac{1}{2}$ Wochen nach der Verletzung, einem Fusstritte) war „von der Iris im ganzen Bereiche der Tridodialyse nur ein $0,225 \mathrm{~mm}$ betragender Stumpf an ihrer Ansatzstelle stehen geblieben." „Der Irisstumpf ist au seiner Oberfläche mit dem schief die inneren ${ }^{2} / 3$ der Sklera (an Stelle der. incompleten Ruptur) durchsetzenden Narbenstrang verwachsen und vorn an seiner Wundfäche etwas in dieses Narbengewebe eingezogen. ... Die Abrisstläche des Stumpfes ist kolbenförmig abgertudet, zeigt ebenfalls einen feinen $\mathrm{Ex}_{\mathrm{X}}$ sudatbelag auf der Vorderfläche, während hier die Pigmentschicht die Ueberkleidung übernommen hat und bis zur Verwachsungsstelle der Stumpfobertläche mit dem Skleralnarbengewebe hinreicht. Der Stumpf erscheint ausserdem beträchtlich infiltrirt." Heftige Cyclitis. -

Schäfer konnte also in seinen zwei Fällen ${ }^{1}$ ) noch deutliche Reste der Iris, welche an ihrem Ciliaransatze stehen geblieben waren, nachweisen, während in meinen Fällen iu Uebereinstimmung mit Treitel's Befund keine Spur der Tris zurïckgeblieben war, ja in dem frisch (4 Tage) nach der Verletzung zur Untersuchung gekommenen Bulbus sogar eine förmliche Heransreissung der Iris ans dem Corpus ciliare nachgewiesen werden konnte.

Die anderen anatomisch untersuchten Fälle, welche sich in der Literatur vorfinden, lassen sich bei Beantwortung der angeregten Frage nicht verwerthen, da die Beschreibungen viel zu kurz gehalten sind (Alt, Schiess-Gemuseus) oder sich (Lawson, Maats) nur auf die makroskopisch wahrnehmbaren Veränderungen beziehen. Welche Einfliisse Schuld daran tragen, dass die Iris einmal quer

1) Den 3. Fall Schäfers [Fall II.] glaube ich nach dem früher Gesagten ausschliessen zu nüssen, da hier nicht eine Abreissung, sondern eine directe Durchschlagung der Iris in der Gegend ihres Ciliaransatzes stattgefunden hatte, Uebrigens war kein Rest der Iris an der Ansatzstelle zurückgeblieben.

v. Graefe's Archiv für Ophthalmologie. Xl. 2. 
durch ihr Gewebe, das andere Mal knapp an ihrer ciliaren Insertion abreisst, lässt sich nach der viel zu geringen Anzahl von Fällen, welche bis jetzt der anatomisch-histologischen Untersuchung zugänglich wurden, noch nicht beur'theilen. Selten werden solche Präparate immer bleiben, zumal da zur Entscheidung dieser Frage nur ganz frisch entstandene oder höchstens einige Tage bestehende Iridodialysen maassgebend sein können.

Es ist selbstverständlich, dass sich nun, je nachdem die Iris vollständig oder mit Zurücklassung eines Stumpfes vom Ciliarkörper abgetrennt ist, auch die Vernarbung im Kammerwinkel verschieden verhalten wird. In letzterem Falle müssen die Verhältnisse ganz ähnliche sein wie an dem kurzen Irisstumpfe, welcher nach Iridectomie zurückbleibt, und auch ähnlich wie an dem abgelösten Stücke der Iris bei Iridodialyse. Diese Verhältnisse bei Verheilung der Iridectomiewunde an der Regenbogenhaut sind von Alt am Kaninchenauge experimentell untersucht worden, wobei er fand, dass die Ueberkleidung der Wundfläche entweder vom Endothel der Vorderfläche der Iris oder vom Pigmentepithel oder schliesslich von beiden übernommen werden kann. Diese Befunde stimmen gut mit den an iridectomirten Menschenaugen überein. Und Schäfer konnte in seinen beiden Fällen die beiden erstgenannten Formen der Verheilung bei Abreissung der Iris constatiren.

Anders ist natürlich die Vernarbung bei $\mathrm{Ab}$ - oder Ausreissung der Regenbogenhaut vom Ciliarkörper ohne Zurücklassung von Resten. Während aber Treitel fand, dass der Verschluss der Wunde im Corpus ciliare durch Narbengewebe bewirkt wird, welches sich direct in die Skleralnarbe fortsetzt und die Ciliarfortsätze zum Theile nach vorn an die Hornhaut hinzieht, komte ich neben dieser Art der Verheilung, wie schon oben erwähnt, noch verschiedene Formen constatiren. Stellenweise legten sich nämlich die Wundflächen der im Ciliarkörper gebildeten Höhlung direct 
an einander und verheilten mit einander, ohne dass eine deutliche Lage von neugebildetem Gewebe zwischen eingeschoben worden wäre. An anderen Stellen wucherte wieder von der Skleralnarbe her so viel Bindegewebe in die Höhlung, dass dieselbe ausgefullt wurde und die Ciliarfortsätze in Folge dessen an die Innenfläche der Narbenmasse angelöthet erscheinen. Wieder an anderen Stellen luxurirte das Narbengewebe in der Sklera so sehr, dass es zapfenartig in das Innere des Augapfels vortritt und den ganzen Vordertheil des Ciliarkörpers sammt den Ciliarfortsätzen in sich aufnimmt oder wenigstens iiberdeckt.

Diese Narbe giebt stets den Ursprung für ein zartes, aus feinfaserigem, kernarmem Gewebe gebildetes Häutchen, in welches auch von hinten und von den Ciliarfortsätzen her sich Zonulafasern einweben und welches den Glaskörperraum vom Kammerraume trennt. Ein derartiges Diaphragma wurde in sämmtlichen bis jetzt zur mikroskopischen Untersuchung gelangten Füllen von Iridodialysis oder Irideremie bei gleichzeitigem Fehlen der Linse nachgewiesen. Dem entsprechend fehlte es natïrich in dem 3. meiner Fälle, wo die Linse, wenn auch verletzt, nooh erhalten war, und ebenso auch in Schäfer's Fall II.; ausserdem wäre auch gerade in diesen beiden Fällen die Zeit offenbar eine zu kurze (4 und 19 Tage) zur Ausbildung einer derartigen Membran gewesen.

Schäfer wirft am Schlusse seiner Arbeit die Frage auf: "Warum blutet es bei einer unter normalen Verhältnissen ausgeführten, regelrecht verlaufenden Iridectomie niemals, wenigstens niemals sichtbar, warum entsteht aber bei einer Iridodialyse immer eine je nach der Ausdehnung derselben mehr oder minder mächtige Haemorrhagie?"

Dieser Fragestellung ist vorerst entgegenzuhaiten, dass es häufig genug auch bei einer regelrecht ausgefiuhrten Iridectomie blutet. Es hängt dies vollständig von dem $\mathrm{Zu}$ stande der Gefässwandungen in der Iris ab; bei alten In- 
dividuen, wo die Gefüsse schon rigid und brüchig geworden sind, kommt es nach der Ausschneidung der Regenbogenhaut immer zu einer mehr oder minder ausgiebigen Blutung und wir besitzen ja auch in der Krankenbeobachtung ein Symptom, welches auf diesen Zufall und auf die Gefässdegeneration von vorne herein aufmerksam macht, nämlich die Unmöglichkeit, die Pupille durch Atropin maximal zu erweitern. Endlich ist es ja eine bekannte Thatsache, dass es bei einer wegen Glaucom ausgeführten Iridectomie, besonders wenn noch Entzündungserscheinungen bestehen, sehr häufig recht heftig blutet. Doch wollte Schäfer diese let\%teren Fälle wahrscheinlich ausgeschlossen wissen, da er von „einer unter normalen Verhältnissen ausgeführten Tridectomie" spricht.

Als Ursachen für die Entstehung der Blutung bei Iridodialyse und Trideremie führt Schäfer Folgendes an: Erstens fasst er die Schnittwunde bei Iridectomie als Quetschwunde auf, welch letztere bekanntlich wenig oder gar nicht blutet. Dem möchte ich jedoch entgegenhalten, dass in der Chirurgie gerade ein wesentlicher Unterschied zwischen Schnittund Quetschwunden gemacht wird und dass es als bekannte Thatsache gilt, dass Schnittwunden ziemlich lange und heftig bluten können, da die Gefässe im gleichen Niveau mit dem umgebenden Gewebe durchtrennt werden, also sich verhältnissmässig wenig zurückziehen können, andererseits auch ganz glatt abgeschnitten werden ohne Zerfaserung ihrer Enden, wie sie bei Riss- und Quetschwunden stattfindet und durch Zerreissung und Einrollung der Intima die primäre Verschliessung des Gefässlumens und spätere Thrombenbildung wesentlich begünstigt.

Zweitens bemerkt Schäfer, dass bei Iridectomie stets ein viel grösserer Stumpf übrig bleibt als bei Iridodialyse, also nur die schon in feinerer Verästelung begriffenen Gefässe durchtrennt werden. Dieses Argument ist jedenfalls als vollkommen richtig anzuerkennen. 
Drittens nimmt Schäfer noch als ein die Blutung bei Iridectomie hinderndes Moment den auch nach Eröffnung der Bulbuskapsel auf dem Bulbusimneren ruhenden Druck der Sklera (nach v. Graefe) und den Druck, welchen die gegen die Hinterwand der Hornhaut vorrückende Linse auf die Iris ausibt, in Anspruch. Doch können beide Gründe keinen Unterschied für Iridodialyse und Iridectomiewunde abgeben, da ja in den zahlreichen Fällen, in welchen früher zur künstlichen Pupillenbildung die Tridodialyse operativ erzeugt wurde, ebenfalls stets heftige Blutung eintrat, wo doch die Druckverhältwisse im Auge genau die-gleichen sind wie bei der Ausführung der Iridectomie.

Als vierter Grund wird angeführt: „Während bei der Iridectomie in Folge der quetschenden Scheerenwirkung die Gefässe aneinander gepresst werden und so eine Thrombosirnng leicht und rasch sich vollziehen kann, findet bei Traumen gerade das Entgegengesetzte statt. Die Gefässwände werden auseinandergehalten und es klaffen besonders "lie Arterien sehr stark in dem spongiösen Irisgewebe." Warum das Letatere der Fall sein soll, bleibt mir unklar.

Als gewiss wichtige Ursache der Blutung bei Irisdialyse wird erwähnt, dass die Gefässe häufig nur angerissen oder der Länge nach eingerissen werden dürften, und dass die Venen der Iris klappenlos sind.

Als Hauptursache nimmt Schäfer jedoch an, „dass als unmittelbare Folge des stattgefundenen und wohl immer, wemn es zu solehen grösseren Verletzungen geführt hat, ziemlich bedentenden Trauma's sowohl in unseren (i. e. seinen) als in allen ähnlichen mit mächtigen Hämorrhagieen verbundenen Fällen vou Iridodialyse eine locale neuroparalytische Gefässlähmung mit Erweiterung derselben eintrat. Wir werden wohl hauptsächlich diesen Umstand als das die Blutung am meisten begünstigende Moment anzusehen haben, welches weiterhin auch den mit am schwer- 
sten in die Wagschale fallenden Unterschied von der Iridectomie abgeben mag."

So richtig diese Ansicht, dass durch das Trauma eine Gefässparalyse erzeugt wird, gewiss ist (und sie ist ja gestützt durch zahlreiche Beobachtungen und Experimente aus der allgemeinen Pathologie von Cohnheim, Leber, Wegner, Salkowski, Nagel), so reicht sie dennoch nicht hin, auch die Blutung in den Fällen von Tridodialyse zu erklären, wo dieselbe lege artis operativ erzeugt wurde, wo also kein grösseres Trauma auf die Iris einwirkte als bei einer Iridectomie; oder man müsste bei der letzteren in Folge des Anfassens der Regenbogenhaut mit der Pincette, was ja auch ein Trauma der Iris bedeutet, ebenfalls eine Gefässparalyse und folgende Blutung erwarten.

Mir scheint es jedoch, dass genügende anatomisch nachweisbare Veränderungen vorhanden zu sein pflegen, welche das Auftreten der Blutung bei Iridodialyse und Irideremie zu erklären imstande sind.

In erster Linie kommt hier in Betracht die Zerreissung des Schlemm'schen Canales. Denn in den drei von mir untersuchten Fällen, wo eine Ruptur der Sklera durch eine stumpfe Gewalt erzeugt worden war (Fall I., II. und IV.), ging der Riss in der Lederhaut genau mitten durch den Schlemm'schen Canal, und in dem 4. Falle (III.), wo die Irideremie durch einen Schrotschuss hervorgerufen war, zeigte sich auch an Stellen, welche weit entfernt von dem directen Angriffspunkte der Gewalt lagen, auch das Ligamentum pectinatum und die Hinterwand des Schlemm'schen Canales eingerissen, so dass sein Inhalt sich frei in den Kammerraum entleeren konnte. Auch in Treitel's Fall ging die Narbe in grosser Ausdehnung durch den Schlemm'schen Canal. In Schäfers Fall I gehörte die breite Narbe zum grösseren Theile der Sklera, zum kleineren der Cornea an; leider wird nichts Positives über ihr Verhältniss zum Leber'schen Venenplexus ausge- 
sagt, eben so wenig wie in dem Fall III, wo über das genauere Verhältniss der im vordersten Theile der Sklera liegenden incompleten Skleralruptur nichts erwähnt wird. Doch scheint es mir gestattet aus dem angegebenen topographischen Verhältniss der Narbe zum Irisstumpfe und aus den Bemerkungen, dass die Narbe in der Sklera lag, aber auch die Descemet'sche Membran eingerissen war, zu schliessen, dass auch in diesem Falle eine Durchtrennung und Eröffnung des Plexus venosus stattgefunden hatte. Was schliesslich die klinisch beobachteten Fälle von traumatischer Irideremie und Iridodialyse anbelangt, so findet sich in der weitaus iiberwiegenden Mehrzahl der mir aus der Praxis und aus der Literatur bekannten Fälle eine ganz nahe dem Hornhautrande gelegene und mit ihm concentrisch verlaufende Skleralruptur (z. B. die Fälle von Irideremie ron Gayet, Carré, Jeaffreson, Samelson, Krajewsky, Dixon, Vose Salomon, Samelsohn, Oeller, Manolescu, Nunnely, Hirschberg, Mengin, Samuel, Mc Keown, Harlan, Natanson, Lyder Borthen, Wadsworth). Dass bei Eroffnung des Schlemm'schen Canales eine sehr ausgiebige Blutung auftritt, besonders dann weun durch Eröffnung der Bulbuskapsel der intraoculäre Druck auf Null abtällt, ist von vorn herein sehr leicht erklärlich, da ja hier ein grosser Theil der Bedingungen fehlt, welche sonst bei Zerreissung von Gefässen der Blutstillung dienen, nämlich Muskelreichthum der Wandung, Contractilität des Getïssrohres und die Möglichkeit, dass sich dasselbe in das umgebende Gewebe zurückzieht. Im Gegentheil wird, da ja der Gefässplexus in das starre Gewebe der Corneoskleralgrenze eingeschlossen ist, das Lumen der zerrissenen Rohre weit klaffen. Es liegen ja auch directe Beobachtungen von Czermak vor über Blutung bei isolirter Zerreissung des Schlemm'schen Canales. Es ist dabei durchaus nicht nöthig, dass die Sklera in einem solchen Falle rupturirt, wie unter anderen mein III. Fall beweist. 
Ein zweiter Grund für das Auftreten der Blutung bei Iridodialyse ist folgender: Fis wird nach meinen Untersuchungen die Iris aus dem Ciliarkörper heraus oder wenigstens knapp an demselben abgerissen. Dabei wird nun der Circulus arteriosus iridis major entweder ebenfalls zerrissen, so dass er in den Schnitten stellenweise gar nicht mehr nachweisbar ist, oder es werden wenigstens die von ihm abgehenden grösseren Getässstämmichen, welche die Iris versorgen, unmittelbar an ihrem Ursprunge alogerissen, wodurch der grosse Iriskreis in ein durchlöchertes Rohr ungewandelt wird, in dem natürlich viel schwerer ein Thrombus sich ausbilden kann. Dabei werden auch gleichzeitig eine grössere Anzahl von Getässen des Corpus ciliare, sowie die Anastomosen mit den vorderen Ciliargefässen durchrissen. Dazu kommt noch das auch ron Schäfer gewürdigte Moment, auf welches v. Stellwag aufmerksam machte, dass bei Eröffnung des Bulbus infolge Contraction der elastischen Fasern der Sklera eine Verengerung der Emissarien und infolge dessen eine Stauung in den Venen stattfindet, welche noch dadurch gesteigert wird, dass wegen Herabsetzung des intraocularen Druckes die arterielle Blutzufuhr erleichtert und vermehrt wird, also Verhältnisse, welche das Zustandekommen einer Blutung ungemein begïnstigen.

Diese zwei anatomisch constatirten Folgen der Iridodialyse und Irideremie genügen auch vollkommen zur Erklärung der Blutung bei operativ erzengter Tridodialysis und Irideremie. Denn nach den Versuchen von Becker, welche Schäfer erwähnt, war bei künstlich erzeugter Irideremie in sämtlichen Fällen mit einer einzigen Ausnahme „die Tris so vollständig entfernt, dass auch nicht eine Spur von ihr nachweisbar war."

Dabei fanden sich fast nur grosse, durchrissene Gefässe, sehr wenig Capillaren. Dass hierbei auch das Liganı. pect. einreisst, ist selbstverständlich und nur allyuleicht 
Beiträge zur patholog. Anatomie d. traumatischen Aniridie etc. 57

kann dasselbe vollständig durchreissen und der Schlemmsche Canal eröffnet werden.

Nach Allem scheint es nur ein sonderbarer Zufall gewesen zu sein, dass Schäfer gerade zwei Augen zur Untersuchung bekam, wo noch Irisreste am ciliaren Ansatze zurückgeblieben waren, während als das gewöhnliche Vorkommen das betrachtet werden muss, dass die Iris sich ohne Zurücklassung von Resten vom Corpus ciliare trennt.

\section{Literatur-Verzeichniss.}

Alt, Studien über die anatom. Gründe und das Wesen der sympathischen Ophthalmie. Knapp's Archiv f. Augen- u. Ohrenheilkunde VI., 2. pag. 267.

Alt, Beiträge zur Kenntniss der anatomischen Verhältnisse des Heilungsvorganges nach Iridectomie. Archiv f. Augenheilk. IV. 2. pag. 240 .

Argyll Robertson, Cas d'irideremie unilatérale apparement d'origine traumatique. Congrès de Londres. Compte rendu pag. $106-111.1873$.

Armaiguac, Contusion violente de l'oel gauche par le choc d'un petard; perte absolue et instantanée de la vue, disparition complète de l'iris; luxation du crystallin dans le corps vitrée. Revue clinique d'oculist. V. pag. 1. cit. nach Nagel's Jahresbericht 1885.

Arlt, Die Krankheiten des Auges. II. Band pag. 121. 1862. Lyder Borthen, Aniridia et aphakia traumatica. Klin. Monatsblätter f. Augenheilkunde 1889 pag. 62 .

Carré, Rupture de la sclerotique, à la partie inférieure, avec arrachement complet de l'iris, qui s'est logé sous la conjonctive, sans luxation du cristallin. France médicale Nr. 43. pag. 338. 1880.

Chisolm, Accidental irideremia or complete removal of the iris by the finger-nail of an antagonist. - Amer. Journ. Med. Soc. Juli 1872 . Vol. 64, pag. 125 u. Lancet I. cit. nach Ophthalmic Hosp. Rep. 1873 pag. 665.

Czermak, Ueber Quetschung des Augapfels mit Bluterguss in die vordere Kammer durch Berstung des Schlemm'schen Canales. Zehender's klin. Monatsbl. f. Augenheilk. 1889 p. 123. 
Deutschmann, Ueber Augenverletzungen und Antisepsis. Beiträge zur Augenheilkunde $1893 \mathrm{Bd}$. I. pag. 8.

Dixon, A Guide to the Practical study of Diseases of the Eye, with an outline of their Medical and Operativ treatment 1855 pag. 374. Cit. nach Makenzie, Maladie de l'oeil I. pag. 604.

Fano, Blessure de l'oeil par corps coufondant. Fracture de la cornée. Decollement de l'iris. Cataracte traumatique. Resorption de la cataracte. Vision retrouvée à un certain degré. Persistance au bout de trois mais de l'acuite normale de l'autre oeil. - Journ. d'oculist. et de chirurgie Nr. 208. 1890 (cit. nach Nagel's Jahresbericht 1890).

Fischer, Lehrbuch der gesammten Entzündungen und organischen Krankheiten des mensehlichen Auges. 1846.

Folker, A case of Evulsion of the Iris. British medic. Journal. 5. Okt. 1872 . t. II. pag. 372 .

Fuchs, Zur Anatomie der Pinguecula. Archiv f. Ophthalmologie XXXVII. 3. pag. 184 Anmerkung.

Galezowski, Anridie traumatique avec luxation du cristallin. Guerison. Recueil d'Ophth. p. 642, 1887.

Gayet, De l'expulsion totale de l'iris par un choc sur le globe oculaire et d'un déformation temporaire $d u$ cristallin. Archiv d'ophthalmologie Jouillet-Aout 1881.

0 Glesby, Removal of the whole of the Iris in an operation for Cataract Ophthalmic Hosp. Reports 1872 pag. 269.

v. Graefe, Archiv für Opbthalmologie VII. 2. pag. 153. 1860.

Haltenh off, Note sur un cas d'aphakie et d'aniridie traumatiques permettant l'observation $d \mathfrak{u}$ fond de l'oeil sans ophthalmoscope. - Congrés médic. internation. de Genêve, Section d'ophthalmologie. - Annales d'oculist. T. 78 . pag. 159.

Harlan, Blow on the eye. Rupture of selero-corneal region. Escape of the lens and of the iris. Good vision with lenses. Ophthalm. Hosp. Reports 1873 pag. 668.

Heyfelder, Beiträge zur Pathologie des Auges und des Gehörorganes. Zeitschrift für die Ophthalmologie von Ammon 4. Band. 1834 pag. 189.

Hirschberg, Zar Casuistik der Augenverletzungen. Zehenders klinische Monatsblätter für Augenheilk. 1869.

- I. Bericht über Dr. Hirschberg's Angenklinik. Berliner Klin. Wochenschrift 1870 pag. 551.

Hjort, Die Ciliarfortsätze während der Aceommodation. Ein 
Beiträge zur patholog. Anatomie d. traumatischen Aniridie etc. 59

Fall von totaler acquirirter Irideremie. Zehenders Klin. Monatsblätter für Augenheilk. 1876 pag. 205.

Homburg, Statistik und Casuistik der Augenverletzungen. Inaugural-Dissertation. Berlin 1883.

Jeaffreson, Cases selected from ophthalmic practic. Case

VIII, Detachement and Extrusion of the Lens and Iris following a Rupture of the Eyeball. Good vision remaining. - Ophthalmic Hospital Reports VII. pag. 191.

Me Keown, Notes of ophthalmic cases. Irish hospit. gaz. May 1. and 15.1873.

Kerschbaumer, Ueber Altersveränderungen der Urea. Archiv f. Ophthalmologie XXXIV. 4 pag. 16.

Krajewski, Verlust der Linse und Iris durch Trauma. Klinika VII. pag. $97-99$ (poln.) cit. nach Nagels Jahresbericht II. pag. 459.1871 .

Lange, Iridodialysis totalis traumatica. St. Petersburger medicin. Wochenschr. Nr. 43. 1879.

- Ein Fall von traumatischer Aniridie und Aphakie. St. Petersburger medicin. Wochenschr. Nr. 34 (V. 279) 1880. Lawson, Injuries of the Fye, orbit and eyelids. Philadelphia 1867 pag. 214. Case LXI. Ophthalm. Hosp. Reports IV. 4. pag, 369 Case V.

Leber, Die Circulations- u. Ernährungsverhältnisse des Auges. Haudbuch Graefe-Saemisch II. Bd. 363 .

Maats, De sympathische Aandoeningen van het Oog. Zesde Jaarlyksch verslag van de Nederlandsch Gasthuis voor Ooglyders 1865 pag. 85 .

Manolescu, Aniridie ct Aphakie traumatiques à gauche. Iridochorioidite sympathique à l'état chronique à droite. Nouveau procédé d'irido-ectomie. Archiv d'ophthalmologie V. Nr. 3 pag. 227. 1885.

Mengin, Contusion de l'oeil droit avec rupture de la sclerotique, luxation sousconjonctivale du cristallin, accompagné et coiffé de tout liris. Vision conservée. Recueil d' Ophth. pag. 502. 1883.

Mooren, Ophthalmiatrische Beobachtungen 1867, pag. 122.

Nagel, Ueber vasomotorische und secretorische Neurosen des Auges. Zehenders klin. Monatsblätter für Augenheilk. 1873 , pag. 405 .

Natanson, Aniridia et aphakia traumatica s powischenjem wnutriglasnawo dawlenja. Westnik ophth. VII. 2, p. 106. 1890. 
Nunnely, Rupture of the Eyeball with loss of lens and iris. Good sight retained. British med. Journal I. pag. 410. 1870 (ref. im Jahresbericht v. Virehow-Hirsch 1870 II. Bd. pag. 414).

Oeller, Ein Fall von traumatischer Aniridie und Aphakie. Centralblatt f. pract. Augenheilk. August 1880.

Oettingen, Klinische Studien. Zur Casuistik der Verletzungen des Auges. Petersburger med. Zeitschr. XI. 1. pag. 18-26. 1866 (ref. in Virchows Jahresbericht 1866, pag. 453).

Rau, Schweizer Cant. Zeitschr. II. 3. 1846 (citirt nach Zander und Geissler, Die Verletzungen des Auges).

Salkowski, Ueber das Budge'sche Ciliospinalcentrum. Zeitschrift für rat. Medicin 1867, XXIX pag, 167 cit. nach Leber in Graefe-Saemisch. II.

Salomon Vose, Ein Fall von Zuriektreten und Unsichtbarwerden der Iris infolge einer Verletzung. British med. Journal. April 1860 (cit. nach Virchows Jahresbericht 1860).

Samelsobn, Traumatische Aniridie und Aphakie mit Erhaltung des Sehvermögens nebst Bemerkungen über die mediale Gesichtsfeldgrenze. Centralblatt $f$. pract. Augenheilk. Juni 1880 , pag. 184.

- Noch einmal die Ciliarfortsătze bei Irideremie. Centralblatt f. pract. Augenheilk. August 1880 .

Samelson, Traumatic aniridia and aphakia. British med. Journ. Nov. 2, 1872 , pag. 498.

- Die Ciliarfortsätze bei Irideremie (und Aphakie). Centralblatt f. pract. Augenheilk. Juli 1880, pag. 213.

Samuel, Association medical journ. 4. Mai 1855, pag. 416 (cit. nach Gaz. hebdom. de médecine et de chirurgie. Mai 1855).

Savary, Disparition totale de l'iris et du cristallin à la suite de contusion de l'oeil. Ann. d'ocul. T. 72, p. 214.

Schäfer, Aniridie und Aphakie; Iridodialysis traumatica. Archiv für Ophthalmologie XXIX. 1. pag. 13.

Schaligin, Abreissung der Iris. Medicin. Bote Nr. 27. 1872 (russ.) [cit. nach Nagels Jahresbericht 1872, pag. 300].

Schiess-Gemuseus, Beiträge zur pathologischen Anatomie des Auges und der Orbita. Archiv f. Ophthalmologie XIV. 1. pag. 91.

- Skleral- und Cornealverletzung, Entfernung des Linsensystems a. der Iris, Heilung mit theilweiser Erhaltung des Sehvermögens. Klin. Monatsbl. f. Augenheilk. 1867 V. p. 82. 
Beiträge zur patholog. Anatomie d. traumatischen Aniridie etc. 61

Stellwag von Carion, Die Ophthalmologie vom naturwissenschaftl. Standpunkte aus. 1853, II. Bd. pag. 70 .

Treitel, Beitrüge zur pathol. Anatomie des Auges. Archiv f. Ophthalmologie XXVI. 3. pag. 83 .

Wadsworth, Rupture of the sclerotic. Boston medic. and surg. Journ. 1868 (ref. in Virchows Jahresbericht 1868 pag. 511).

Wegner, Experimentelle Beiträge zur Lehre vom Glaucom. Archiv f. Ophthalmologie XII. 2, pag. 1.

Weller, Die Krankheiten des menschlichen Auges. 1822, pag. 320 Anmerkung.

Williams, Case of injury of the eye, resulting in total loss of the iris and lens, with the establishment of a permanent fistula of the sclerotic nearly perfect vision being recovered. Dublin. Quat. Journ. Aug. 1864 (ref. in Virchows Jahresbericht 1864).

Wintersteiner, Ein Fall von traumatischer Aniridie. Wiener klinische Wochenschrift 1893 , Nr. 6.

Erklärung der Abbildungen auf Taf. I u. II.

Fig. 1. Fall I. Verticaler Durchschnitt durch die vordere Bulbushälfte. Skleralruptur mit Irisprolaps $(J P)$. Die abgerissene Iris $(J)$ der gegenüberliegenden Seite ist umgeschlagen und herübergezogen. Das abgelöste Irispigment $(P)$, kleidet die vordere Hälfte des subconjunctivalen Hohlraumes aus.

Fig. 2. Fall 1. Bindehaut in der Umgebung des Irisvorfalles. Schwache Vergrösserung. Vebersicht über die Vertheilung des Pigmentes in den perivascularen Lymphscheiden und im subconjunctivalen Gewebe.

Fig. 3. Getässquerschnitt aus der Conjunctiva mit pigmentführenden Leucocyten in den perivascularen Lymphräumen.

Fig. 4. Pigmentirung der Bindegewebskeme des subconjunctivalen Gewebes. Eine pigmentführende Wanderzelle.

Fig. 5. Pigment in den Basalzellen des Bindehantepithels.

Fig. 6. Fall III. Verticaler Durchsehnitt durch die vordere Bulbushälfte. Die Hornhaut bes. in den hinteren Schichten infiltrirt. Schusscanal unten an der Corneo-Skleralgrenze. Ciliarkörper daselbst abgelöst, von einem Rundzellenheerde überdeckt, in dessen Mitte die quergeschnittene Cilie sich befindet. Irideremie. Linse subluxirt, ihre Kapsel am Aequator zerrissen, beginnende Cataracta traumatica. Fibrin- und Blut- 
gerinnsel in der Kammer und im Glaskörper. Netzhaut, Chorioidea und Ciliarkörper abgelöst.

Fig. 7. Fall III. Schnitt durch die Corneoskleralgrenze bei Irideremie. Zerreissung des Ligamentum pectinatum, Eröffinung des Schlemm'schen Canales. Wundhöhle, entstanden dureh Herausreissen der Iris aus dem Ciliarkörper. Ein grösseres Gefäss desselben ist angerissen, die Wunde durch Thrombose geschlossen. Blutung aus dem Schlemm'schen Canal in die Vorderkammer.

Fig. 8. Fall IV. Vertikaler Durchschnitt durch den vorderen Bulbusabschnitt bei doppelter Iridodialyse. Incomplete Skleralruptur oben und unten. Die abgetrennte Iris an dem zarten Diaphragma fixirt, welches den Glaskörper nach vorne abgrenzt. Aphakie.

Fig. 9. Fall. IV. Corneoskleralgrenze innen. Skleralruptur. Vorfall der dialysirten Tris. Hinter derselben liegt in der Wunde junges Narbengewebe.

Fig. 10. Fall IV. Corneoskleralgrenze innen oben. Skleralruptux. Die vorgefallene Iris reicht kanm mehr durch die ganze Dicke der Skleralwunde.

Fig. 11. Fall IV. Corneoskleralgrenze aussen oben. Uebergang der Dialyse in die normale Anwachsung der Iris. Incomplete Skleralruptur. Die dialysirte Iris ist durch einen Faden mit dem Lig. pectin. verbunden.

Fig. 12. Fall IV. Corneoskleralgrenze aussen unten. Sklera und Schlemm'scher Canal intact. Ligam. pectinat. eingerissen, die Ciliarfortsätze an dasselbe fixirt.

Fig. 13. Fall IV. Corneoskleralgrenze innen unten. Complete Skleralruptur, welche durch massiges, in die Kammer vorspringendes Narbengewebe ausgefüllt ist. Ciliarfortsätze an die Hinterfläche der Narbe angewachsen. Unter der Conjunctiva noch Reste der vorgefallenen Iris. (Vgl. Fig. 9.)

Fig. 14. Fall V. Iridodialysis duplex. Luxatio lentis sub conjunctivam. Ciliarfortsätze durch die innere Dialyse sichtbar.

Fig. 15. Fall VI. Iridodialysis duplex. Cicatrix corneae c. prolapsu iridis cicatrisato.

Fig. 16. Fall II. Schnitt oberhalb des horizontalen Meridians durch den inneren Corneoskleralbord. Ruptur der Sklera knapp an der Hornhautgrenze, Vorfall des Corpus ciliare. Dasselbe atrophisch, der pigmentirte Ueberzug zerworfen, zum Theil in das den Prolaps überkleidende Narbengewebe verschleppt. Wundspalt zwischen Cornea und Vorfall. Der Ciliarkörper vor der Ora serrata abgerissen, mit Blutcoagulis bedeckt. 


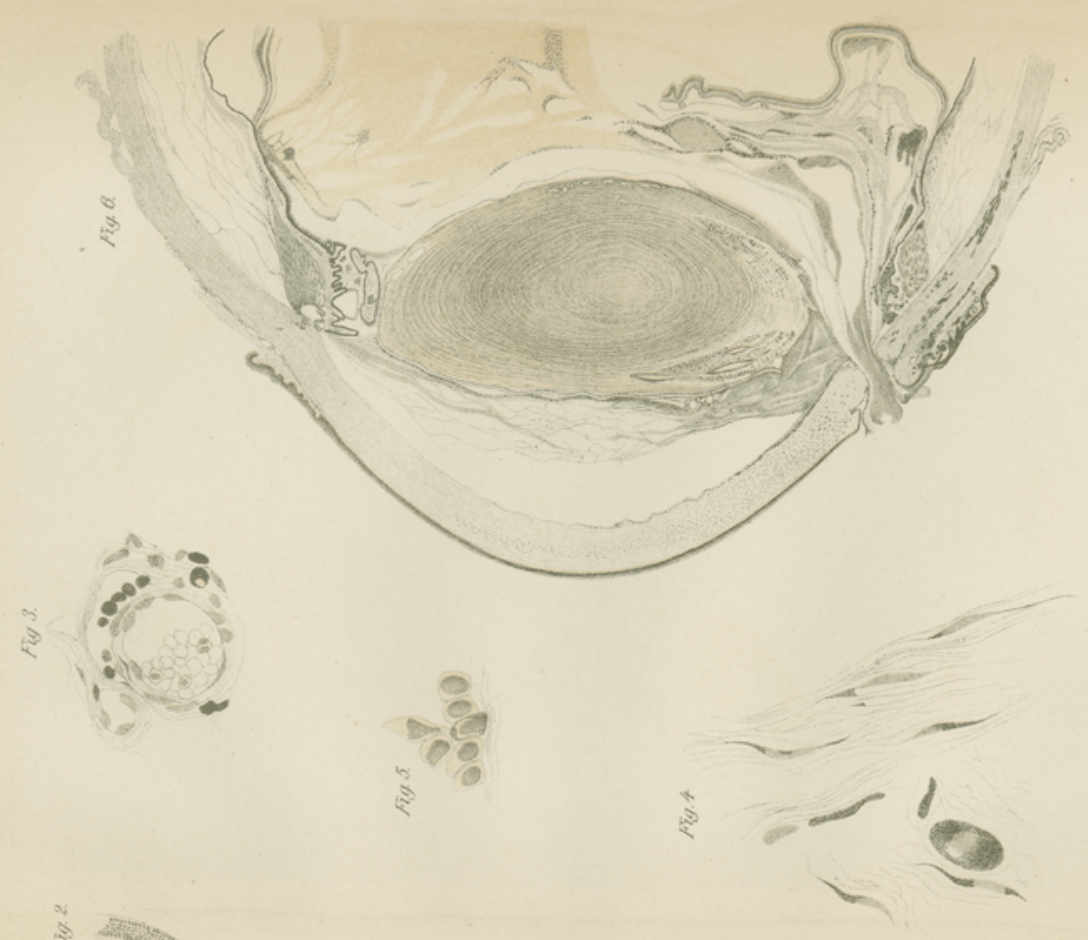

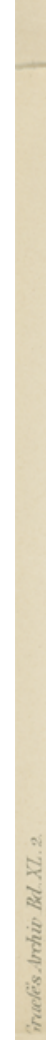

10 is

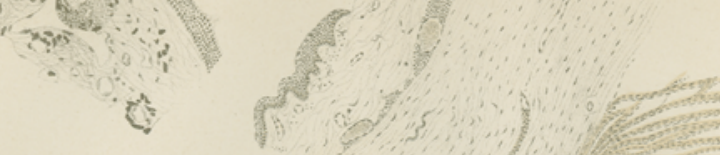
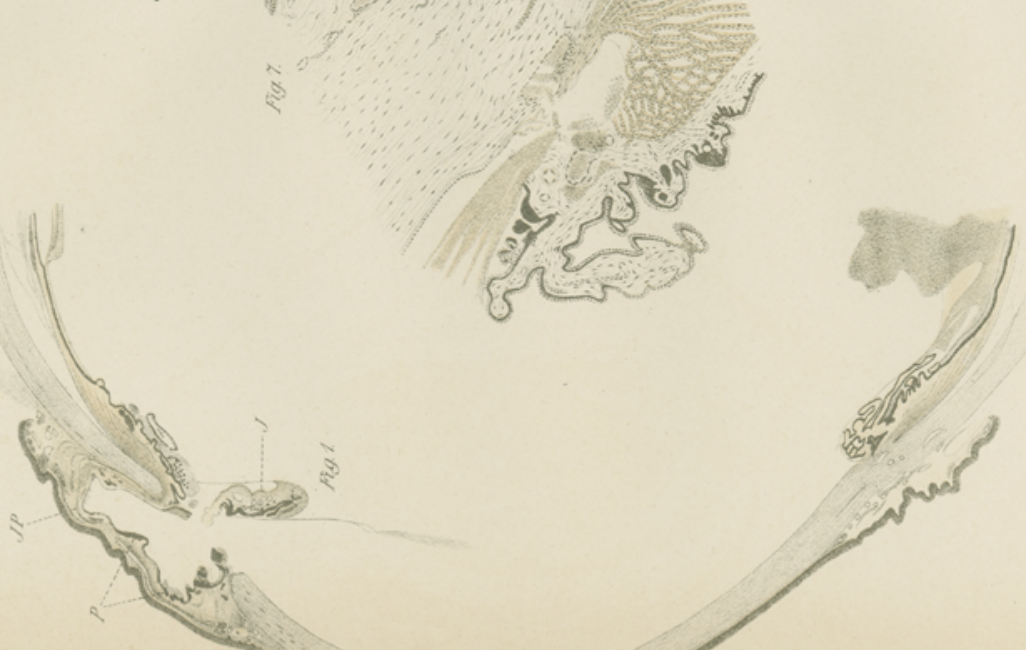


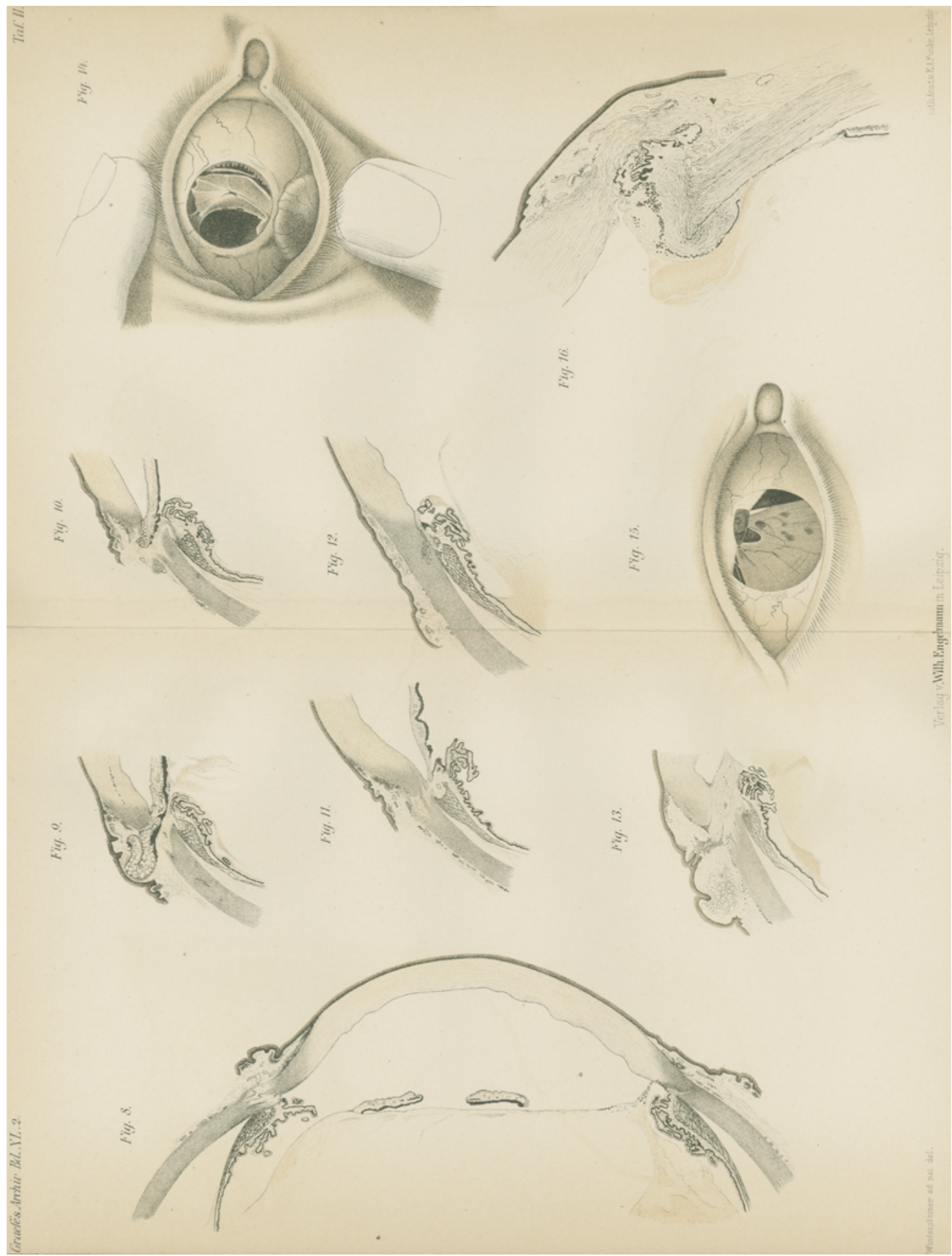

